COMPARISON OF SIMPLE MOVING AVERAGE AND ARIMA TIMESERIES FORECASTING MODELS ON INDEPENDENT HISTORIC DATA AND EXTRAPOLATING ECHO PROGRAM ATTENDANCE

\author{
A Thesis \\ presented to \\ the Faculty of the Graduate School \\ at the University of Missouri-Columbia
}

In Partial Fulfillment

of the Requirements for the Degree

Master of Health Informatics

by

SARA KASUKURTHY

Dr. Lincoln Sheets, Thesis Supervisor

JULY 2021 
The undersigned, appointed by the Associate Vice Chancellor of the Office of Research and Graduate Studies, have examined the thesis entitled

\section{COMPARISON OF SIMPLE MOVING AVERAGE AND ARIMA TIMESERIES FORECASTING MODELS ON INDEPENDENT HISTORIC DATA AND EXTRAPOLATING ECHO PROGRAM ATTENDANCE}

presented by Sara Kasukurthy, a candidate for the degree of Master of Health Informatics, and hereby certify that, in their opinion, it is worthy of acceptance.

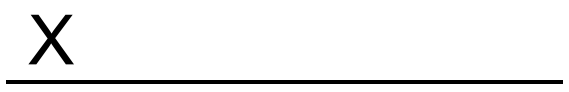

Professor Lincoln Sheets

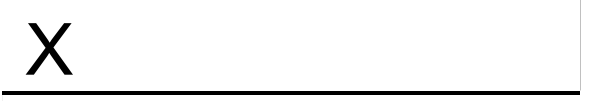

Professor Sue Boren

Professor Mirna Becevic 


\section{ACKNOWLEDGEMENTS}

Foremost, I would like to express my sincere gratitude to my advisor Prof. Lincoln Sheets for the continuous support of my master's thesis work for his patience, enthusiasm, and immense knowledge. His guidance and encouragement helped me in both research and writing of this thesis. Besides my advisor, I would like to thank the rest of my thesis committee: Prof. Sue Boren, for her encouragement, insightful comments and perspectives and Prof. Mirna Becevic, for offering me the summer internship opportunity which helped me to enroute my thesis work on diverse project.

My sincere thanks also go to Missouri Telehealth Network Organization and the entire team for their generous attitude and friendly behavior gave me the opportunity to increase my knowledge in emerging technologies of health system. Also, I wish to extend my heartfelt regard to the whole Health Management and Informatics Department for helping me to experience many meaningful learning experiences. 


\section{TABLE OF CONTENTS}

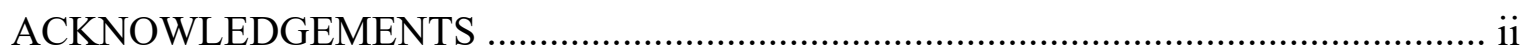

LIST OF ILLUSTRATIONS …........................................................................... iv

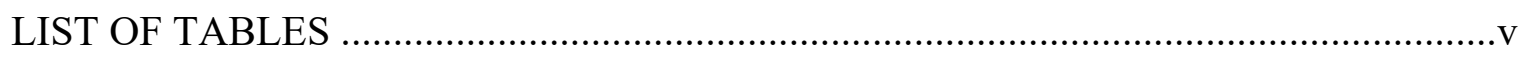

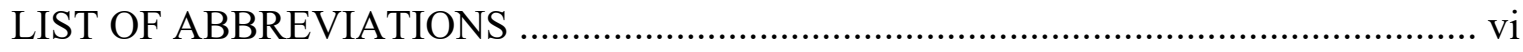

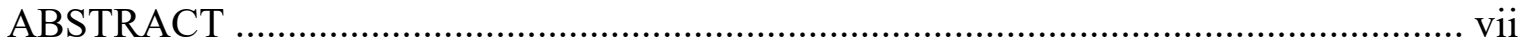

Chapter

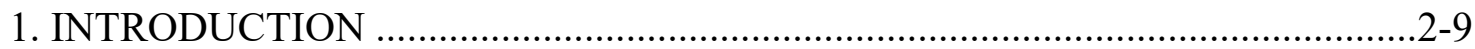

2. SYSTEMATIC LITERATURE REVIEW .........................................................11-16

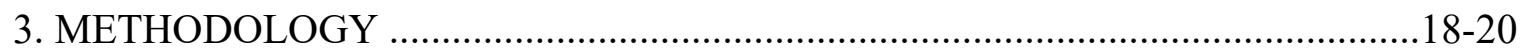

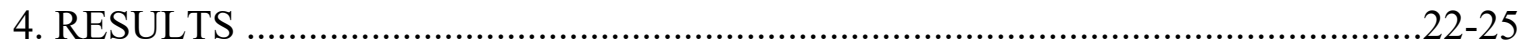

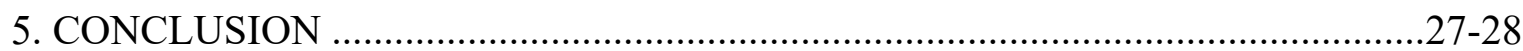

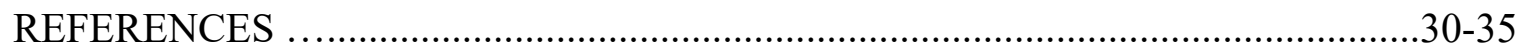

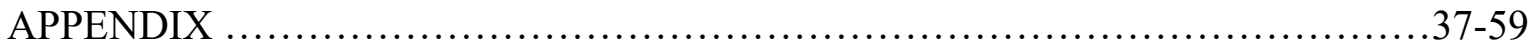




\section{LIST OF ILLUSTRATIONS}

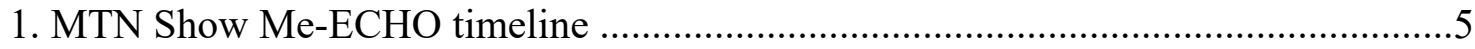

2. Available Data in MTN Show Me-ECHO ...................................................5

3. Current Data flow \& proposed for Daily Operations in MTN - ECHO .............6

4. Current Data flow \& Proposed for Evaluation in MTN - ECHO .....................6

5. Time Series Components ................................................................................

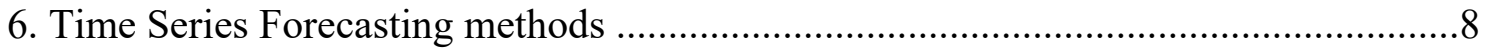

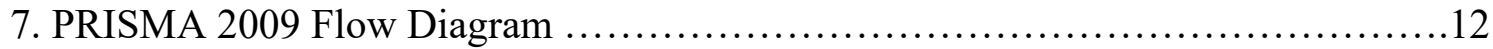

8. Data Observations \& Analysis Study Process ........................................................20

9. Comparison of SMA and ARIMA forecasting models $(2015-2019)$...............24

10. Attendance both Actual Past (2015-2019) and Future Predicted (2020-2025) ......25 


\section{LIST OF TABLES}

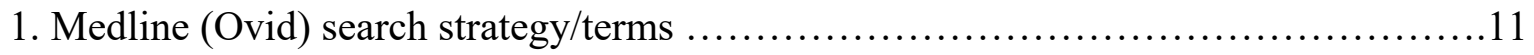

2. Show-Me ECHO Disease Variables ...................................................................22-23

3. Comparison of SMA and ARIMA forecasting models $(2015-2019) \ldots \ldots \ldots \ldots \ldots \ldots . . .24$

4. Future Predicted Attendance (Simple Moving Average Forecasting) (2020-2025) ........25 


\section{LIST OF ABBREVIATIONS}

ECHO - Extension of Community Healthcare Outcome - program

AR - Autoregressive

MA - Moving Average

CMA - Centered Moving Average

SMA - Simple (Arithmetic) Moving Average model

ARIMA - Autoregressive Integrated Moving Average model

SARIMA - Seasonal Multiplicative Autoregressive Integrated Moving Average model

VARIMA - Vector Autoregressive Integrated Moving Average model

ES - Exponential Smoothing model

ADF - Augmented Dickey Fuller test

KPSS - Kwiatkowski-Phillips-Schmidt-Shin test

MAE - Mean Absolute Error

MSE - Mean Square Error

MAPE - Mean Absolute Percentage Error

PCP - primary care providers

CME - Continuing Medical Education

UNM - University of New Mexico

RedCap - Research Electronic Data Capture Software

NCRR - National Center for Research Resources 


\begin{abstract}
Background: The Extension of Community Healthcare Outcome program (ECHO) is an educational and training telemedicine service that provides voluntary case-based learning opportunities for healthcare professionals. Prediction of participant attendance will be useful to improve the sessions with early requirements to maximize the benefits. Usually, the most sophisticated Auto Regressive models are used for forecasting, when the data contains observation with multiple variables and dependencies, Simple Moving Average (SMA) models are used less in such conditions. In this study we want to examine the accuracy and reliability of Moving Average models compared with Auto Regressive models. The objective of this work is to develop an accurate forecasting model for ECHO program attendance by considering non-stationary, independent organizational data.
\end{abstract}

Methods: The study analyzed 2015-2019 Show Me ECHO attendance data from the Missouri Telehealth Network (MTN). The first step; trained and tested both SMA and ARIMA predictive models without any dependent variables and evaluated both models by measuring error values. The second step; used the best model to forecast ECHO attendance for years 2020 - 2025 .

Results: The SMA model was better than the ARIMA model for independent data with lower error values MAE - 38.9, MSE - 2552.15, MAPE - 32.9\%, p- value: 3.36E-28, and higher R - square: 87\%. Where ARIMA model was with higher error values MAE - 61.8, MSE - 7198.88, MAPE $37.7 \%$, p-value: $6.25 \mathrm{E}-22$, and lower $\mathrm{R}$ - square: $80 \%$.

Conclusion: Simple Moving Average (SMA) is more accurate than Autoregressive Integrated Moving Average (ARIMA) in forecasting future ECHO program attendance. Based on prediction; In 2019, the attendance range was 250-550, where in 2025 it got increased to 530-1170; shows that telehealth attendance will be doubled in the next five years. 


\section{Chapter I INTRODUCTION}




\section{Telehealth ECHO programs}

ECHO (The Extension of Community Healthcare Outcomes) project is an innovative approach for tele-mentoring of primary care providers (PCPs) practicing in rural, remote, and underserved communities using live-interactive video technology with oral presentations and sharing advanced practice ideas between hub and spoke members to facilitate best practices for patients. [1,2] Project ECHO was a model developed from the idea (future vision) of Dr. Sanjeev Arora, a Hepatologist and Gastroenterologist in University of New Mexico in 2003 to treat (address the growing hepatitis C epidemics) many of Hepatitis $\mathrm{C}$ patients throughout the state. $[1,3,4]$

The objective of ECHO model is to provide tele-mentoring and education in best practices, to increase PCPs' capacity to care for patients with complex and chronic conditions, removing some of the access barriers patients might face. [5] The core design of this program includes videoconferencing to merge various interprofessional teams ("hubs") delivering regularly scheduled sessions across multiple health care settings. The subject matter specialists serve as "hub" while "spoke" includes PCPs, nurses, physician assistants and other health care professionals. $[5,6]$ The ECHO model further encourages "all-teachall-learn" environment, knowledge sharing beyond one-on-one teaching or discussions. [5]

During each ECHO session the hub team specialists deliver a 10-15 minute didactic, followed by one or more real time patient case presented by participants and used for mentoring and education. [7] Organizations conduct sessions typically weekly or monthly, some ECHOs are year-round, while other follow academic calendars or other individual schedules. One of the main goals of ECHO program is to share latest evidence-based 
recommendations and guidelines to reduce variation in care between rural and underserved, and urban areas.

In some isolated areas and rural areas, for providers they have very little opportunities to expand their knowledge with other colleagues and to continue their education with according to the new developments and achievements. Also, they may not contain fullfledged equipment, complex procedures to maintain beneficiary treatment for patients with chronic illnesses. Sometimes it will be a major drawback for uninsured patients where they lack quality (high) care services. If primacy care providers in rural areas want to consult with specialties for their patients, they may have limited access to such things, or they may get other difficulties to do so. In these conditions these ECHO sessions are very useful to provide better treatment for patients in less time, with low cost and it is very effective in actions. The committee on ECHO team will share various better ideas among them and will give a best option of treatment through video conferencing. [8]

There are currently $960 \mathrm{ECHO}$ programs from 436 hubs in 45 countries globally. ${ }^{5}$ Of those, 642 programs and 257 hubs are in the United States (as reported on 1/6/2021). [9] As the ECHO model continues to grow and replicate in various clinical and non-clinical applications, it is evident that administrators and other stakeholders will need robust and systematic program evaluation to inform about the effectiveness and efficacy of ECHO.

\section{Evaluation Approach -}

ECHO program which adheres to best practices needs proper evaluation process to know the advantages and disadvantages, improvements or to be implemented for better participant experience and satisfaction of involvement. [10] When it comes to research 
needed for project $\mathrm{ECHO}$, the priority will be given for evaluation of ongoing project implementations to remodel it as an effective tool for knowledge transfer and for sharing respective experiences of "hub and spoke" members to discuss and improve health care delivery outcomes. Through evaluation approaches we can consider analyzing opportunities like individual provider participation and continuation, involvement of health care organizations, extent of spread/adaptation, positive delivery systems, performance identification and aspects such as organization of specialist teams (hub), primary care provider recruitment, workflow of care delivery support for remodeling/further improvements. [11]

The evaluation of ECHO project includes either process, outcome or economic evaluations. Process evaluation is about program goals and implementations, participants number and characteristics (like whether physician, nurse or other health care providers), project model and activities, accomplishments and outcomes. [12,13] Outcome evaluation will focus on assessing the outcome results such as improvements in knowledge and self-efficacy, changes in treatment practices, professional satisfaction and confidence, patient outcomes, costs and care utilization variations/changes. [14] Economic evaluation includes expenses for implementations, program deliveries for the benefits obtained from sessions, ROI (return on investment) calculations, cost effective, efficient and benefit analyses. [15] This evaluation can be done with different program performance measuring models such as, Kirkpatrick evaluation and Moore evaluation which guides perfectly in measuring specific program efficiency and effectiveness. 


\section{MTN Show-Me ECHO -}

Missouri telehealth network (MTN) started Show Me ECHO program with pain management sessions in November 2014 (move knowledge not patients). Since then, it is growing in a fascinating way which has 108 counties across Missouri state and 790 organizations involvement/participation in overall 35 ECHO topics till July 2020. Also, MTN Show Me ECHO program is one of 13 global super hubs for training other organizations to start/create ECHOs.

Figure 1: MTN Show Me-ECHO timeline

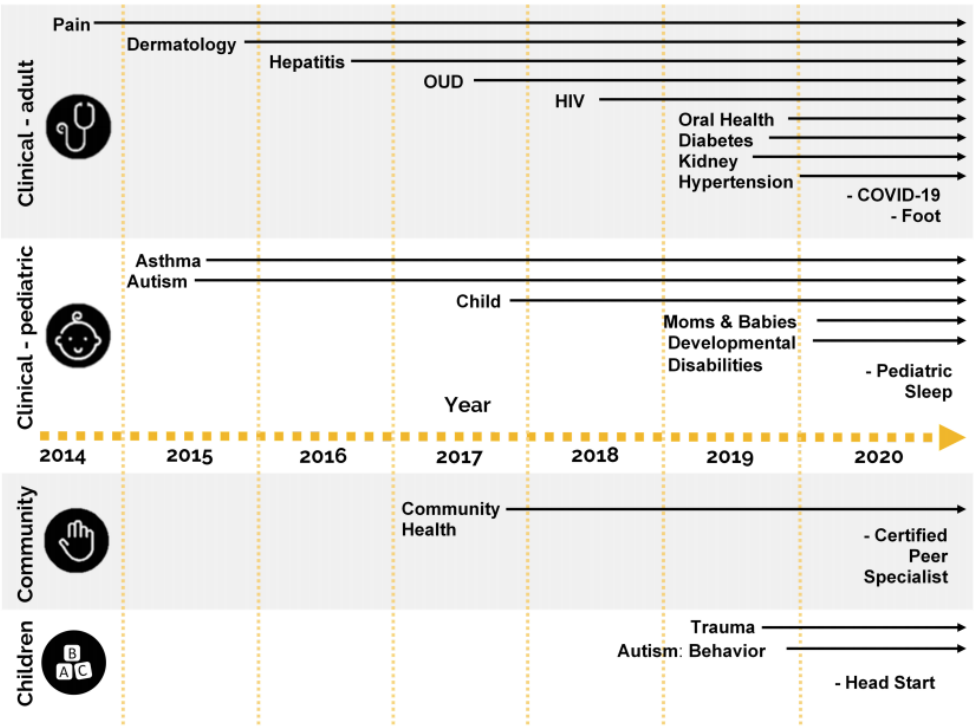

Figure 2: Available Data in MTN Show Me-ECHO

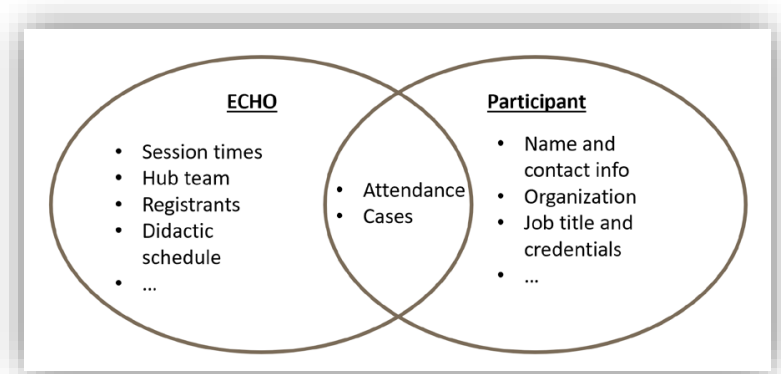


For data collection process Missouri Telehealth Network usually follows through RedCap, which is safe and secure, for registrations (registers interest in a topic) \& pre-survey, roll call (before every individual session), case presentation (participant) and recommendation (hub team) forms, semi-annual self-efficacy surveys (and any additional question), opt-out (exit survey). Data storage through MarketVolt - email marketing software for General communications, weekly session invitations (with links) and $\mathrm{iECHO}$ which is required by Project ECHO for session attendance information and for Being phased out (both by Project ECHO and MTN). Box will be using for document storage with excel, SAS, SPSS files, just obtained for analysis.

Figure 3: Current Data flow \& proposed for Daily Operations in MTN - ECHO
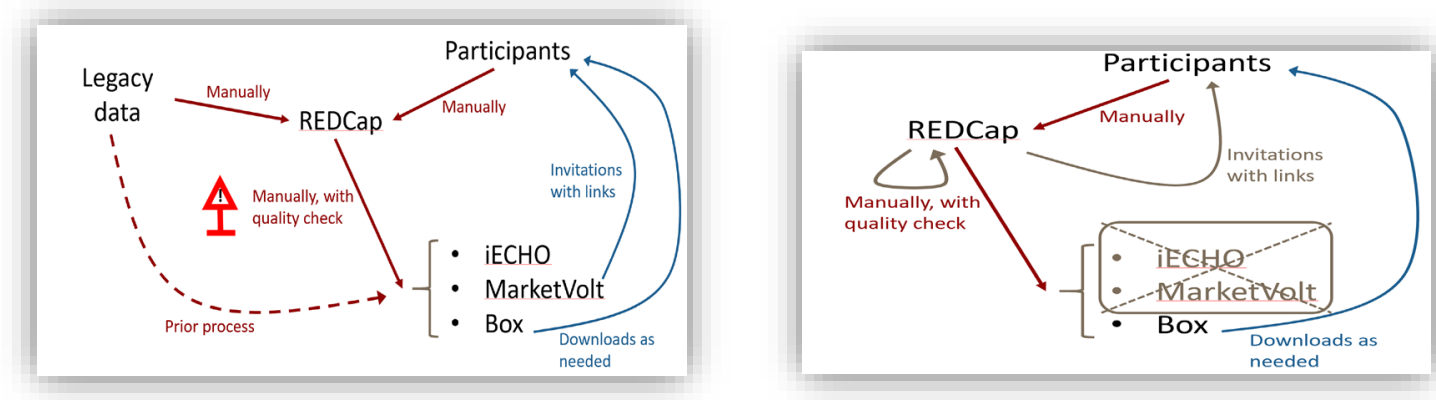

Figure 4: Current Data flow \& Proposed for Evaluation in MTN - ECHO
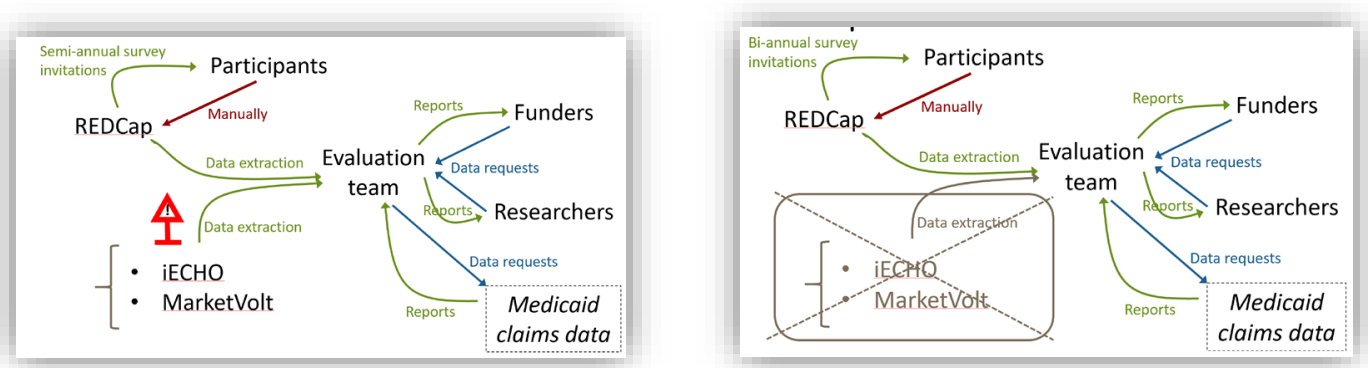


\section{Time series analysis}

Time series analysis involves developing models that best capture or describe an observed time series to understand the underlying causes. The four components that time series analysis will decompose the data into an estimation are secular trend, seasonal variations, cyclical fluctuations, and irregular variations, each expressing a particular aspect of the movement of the values of the time series. [16]

Figure 5: Time Series Components

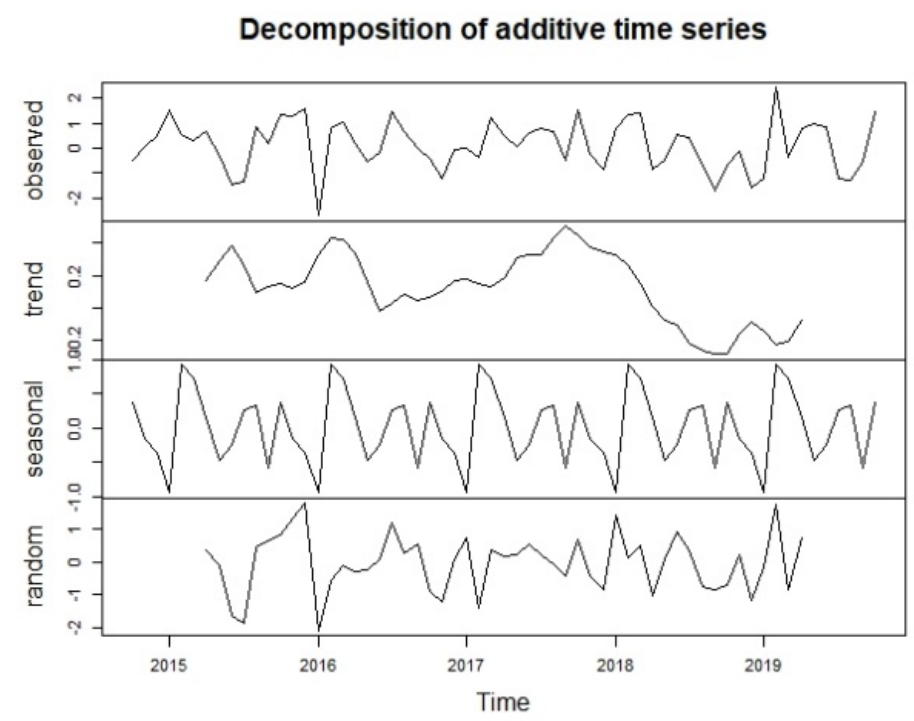

Some important data characteristics involved in time series analysis are data stationarity, seasonality, and autocorrelation. Stationarity - when the statistical properties of data do not change according to time, when the data has constant mean, variance, and covariance with independent of time, that means the data is stationary. Mostly time series models are used on non-stationary data by converting that to stationary. Usually, regression models are effective on data which has dependent variables and moving average models on data with independent variables. Seasonality - the characteristic of periodic fluctuations and 
changes in data points trend according to seasons is knows as seasonality in data. Autocorrelation - means the similarity between observations as a function of time lag between them. [17]

\section{Time series forecasting}

Forecasting involves taking models fit on historical data and using them to predict future observations. The three general types of forecasting techniques used for organizational data for predictions are qualitative techniques, time series analysis and projection and causal models. Time series analysis consists of moving average, exponential smoothing, trend projections and Box-Jenkins technique, causal model contains mainly regression models. The five common algorithms are Linear Regression (LR), Simple Moving Average (SMA), Autoregressive Moving Average (ARMA), Autoregressive Integrated Moving Average (ARIMA), Exponential Smoothing (ES). [18]

Health care organizations need forecasting method implementations to manage decision making for health services and the four major common forecasting methods are 12-month moving average, trendline, percent adjustments and seasonalized forecast, which are dependent on recent historical data demand of organization. [19]

Figure 6: Time Series Forecasting methods

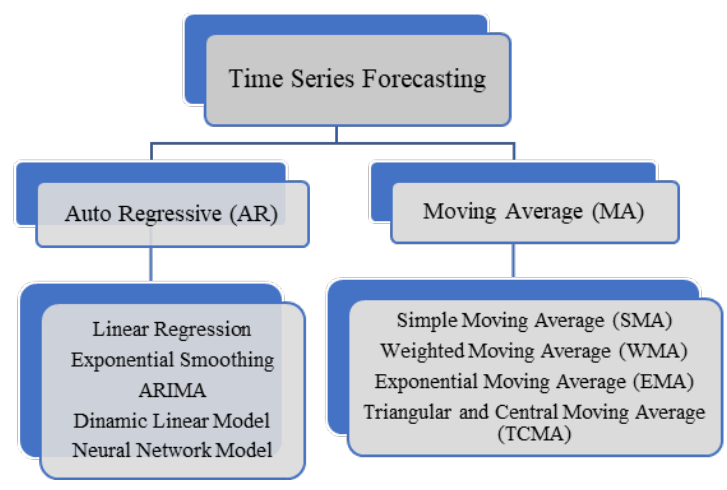




\section{Objectives}

1. Implementation and comparison of both Simple Moving Average and ARIMA time series models on organizational independent data to find out which time series model is well fitted for predicting future values?

2. Forecasting future ECHO participants attendance using more efficient time series model for future implementations and improvements and to support thesis hypothesis "Telemedicine ECHO project awareness/progression and health professional's participation will increase in the future". 


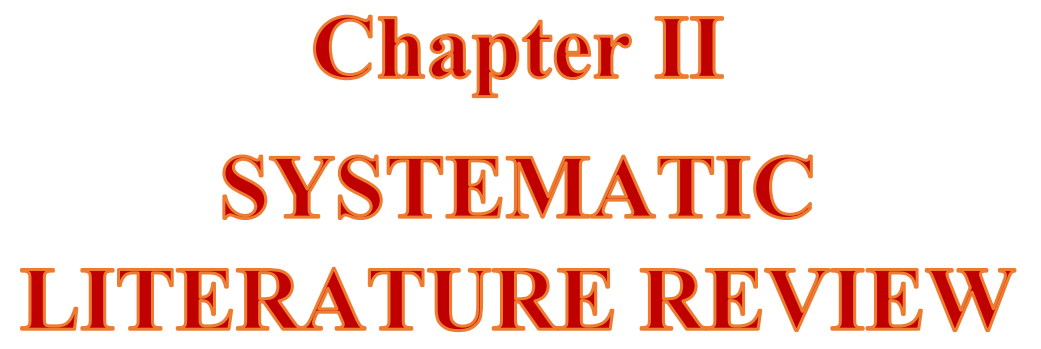


An electronic literature search was performed in MEDLINE (OVID) with inclusion criteria of certain keywords and articles from 1946 to May 04, 2021.

Search Keywords: Time series analysis, time series forecasting, prediction, moving average, ARIMA, autoregression, evaluation of time series forecasting.

Table 1: Medline (Ovid) search strategy/terms

\begin{tabular}{|l|l|l|}
\hline S. No & Search Terms & Results \\
\hline 1 & time series analysis.mp. & 5724 \\
\hline 2 & forecasting.mp. or Forecasting/ & 91747 \\
\hline 3 & moving average.mp. & 2507 \\
\hline 4 & ARIMA.mp. & 904 \\
\hline 5 & autoregressive integrated moving average.mp. & 700 \\
\hline 6 & evaluation of time series.mp. & 17 \\
\hline 7 & 3 and 4 & 4501 \\
\hline 8 & 3 and 4 and 5 & 408 \\
\hline 9 & 2 and 6 & 3 \\
\hline 10 & 2 and 3 and 4 & 137 \\
\hline 11 & limit 10 to (English language and full text) & \\
\hline
\end{tabular}

Considered 177 articles from "forecasting and moving average and ARIMA" keyword combination search and three articles about evaluation methods were also considered for initial screening. After removal of 87 duplicates, 93 were screened for availability of full text and selected 16 articles under eligibility and 3 free web search articles were included to the list. Total 19 articles were selected, many of them stating the same point for conclusion that ARIMA model is highly considerable among regression models, here selected 7 articles, one each of different statements for decision making of procedures. 
Figure 7: PRISMA 2009 Flow Diagram
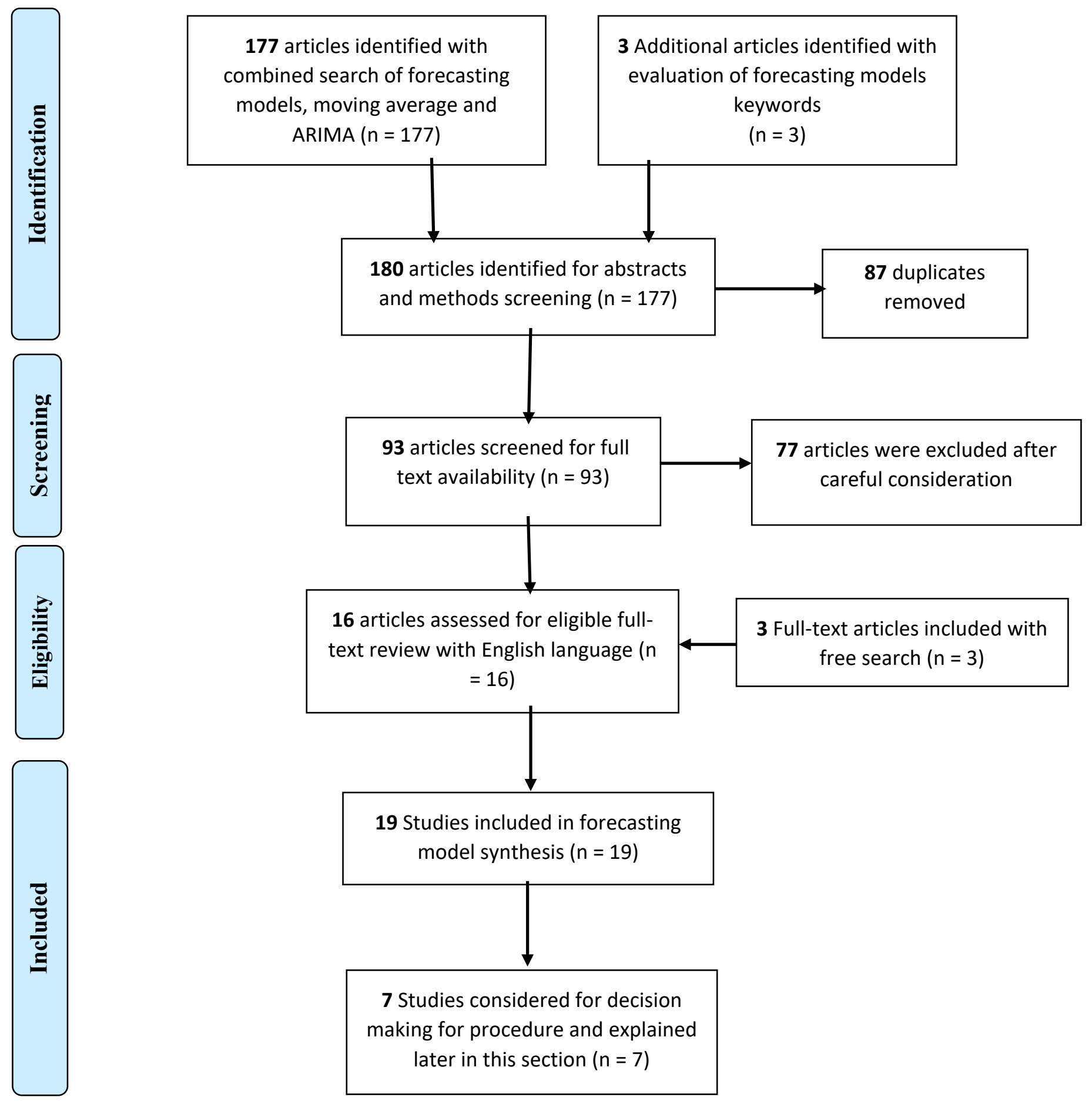


\section{Zoran Ivanovski, Ace Milenkovski, and Zoran Narasanov. 2018. Time Series Forecasting Using a Moving Average Model for Extrapolation of Number of Tourist. UTMS Journal of Economics 9 (2): 121-132.}

The study consists of quarterly data for total number of guests for the five years period from 2012-2016 and extrapolated number of guests quarterly for 2017. The authors in this study stated that moving average model is the most suitable forecasting approach when the observations mainly depend on error terms, means not on past values or on any other dependent variables and which follows a white noise process (purely random in nature). They observed relatively small difference between actual and forecasted values for the first two quarters of 2017 ( $8 \%$ and 1\%), so concluded that the moving average time series model provides accurate forecasting values for independent data and this is the starting point for my thesis about proving Moving Average model is the best model compared to Autoregressive models. [20]

2. Aryee, G., Kwarteng, E., Essuman, R., Nkansa Agyei, A., Kudzawu, S., Djagbletey, R., Owusu Darkwa, E., Forson, A. (2018). Estimating the incidence of tuberculosis cases reported at a tertiary hospital in Ghana: a time series model approach. BMC Public Health, 18, 1292.

The main aim of considering this study was to assess the effectiveness of ARIMA time series model to estimate the incidence of TB cases at teaching hospital. They conducted auto regressive integrated moving average (ARIMA) model on monthly cases to see the trends and seasonal changes in number of patients presenting with TB worldwide from 2008 to 2017 . They finalized ARIMA $(1,0,1)$ as best model which produced 0.971 AR coefficient and -0.826 MA coefficient. Further they forecasted monthly values for 2018 
with the best model they obtained (ARIMA $(1,0,1))$ and observed the different range between 50-55. [21]

\section{Briet, O. J., Vounatsou, P., Gunawardena, D. M., Galappaththy, G. N.,} Amerasinghe, P. H. (2008). Models for short term malaria prediction in Sri Lanka. Malaria Journal, 7, 76.

The main aim of the study was to develop a forecasting system which could be used to assist in the efficient allocation of resources for malaria control, by considering a long time series of monitored/diagnosed malaria cases for the study of forecasting models. They conducted and compared Exponentially weighted moving average models, autoregressive integrated moving average (ARIMA) models with seasonal components, and seasonal multiplicative autoregressive integrated moving average (SARIMA) models on monthly time series cases to check model ability in predicting numbers for one to four months ahead. They found out that the best model varied distinctly throughout the districts and forecasting horizons, but most often SARIMA class models showed least mean absolute relative prediction errors. [22]

4. Loha, E., Lindtjorn, B. (2010). Model variations in predicting incidence of plasmodium falciparum malaria using 1998-2007 morbidity and meteorological data from south Ethiopia. Malaria Journal, 9, 166.

In this study, researchers implemented 35 models on data consists P. falciparum malaria incidence for the period of 1998-2007 and meteorological variables such as monthly rainfall (all locations), temperature (17 locations), and relative humidity (three locations) and considered R squared or stationary $\mathrm{R}$ squared values to measure the model fitness. 
Time series modelling was carried out using Transfer Function (TF) models and univariate auto-regressive integrated moving average (ARIMA) when there was no significant predictor meteorological variable. They observed R squared values for the models ranged from $16 \%$ to $97 \%$, except for one model which had a negative value and models with seasonal ARIMA orders were found to perform better, so considered ARIMA model as the second forecasting model to compare with Moving Average model. [23]

5. Mai, Q., Aboagye-Sarfo, P., Sanfilippo, F. M., Preen, D. B., Fatovich, D. M. (2015). Predicting the number of emergency department presentations in western Australia: a population-based time series analysis. Emergency Medicine Australasia, 27, 16-21.

The main aim of the study is predicting number of emergency department presentations in the next five years with the data consists of dependent variables like place of treatment, age, triage and disposition. They considered monthly data from years 2006/07 - 2012/13 financial years and used univariate autoregressive integrated moving average (ARIMA) and multivariate vector-ARIMA techniques. The findings are ED presentations in WA were predicted to increase from 990342 in 2012/13 to 1250991 (95\% CI: 982 265-1 519 718 ) in $2017 / 18$, an increase of 260649 (or 26.3\%) and majority of increase they found in metropolitan WA (84.2\%). Concluded that time series analysis, particularly VARIMA is most reliable tool for predicting demand by categories. [24]

6. N'gattia, A. K., Coulibaly, D., Nzussouo, N. T., Kadjo, H. A., Cherif, D., Traore, Y., Kouakou, B. K., Kouassi, P. D., Ekra, K. D., Dagnan, N. S., Williams, T., Tiembre, I. (2016). Effects of climatological parameters 


\section{in modeling and forecasting seasonal influenza transmission in}

\section{Abidjan, cote d'ivoire. BMC Public Health, 16, 972.}

The main aim of the current study is to identify and model the effects of climatological parameters on seasonal influenza activity and forecasting values for ahead of time. They conducted multivariant and univariant autoregressive integrated moving average model (ARIMA) to create models on data from 2007-2010 and to assess the predictive values by best fitted model on data from 2011 - 2012 and compared both performances based on Akaike Information Criterion (AIC) and Bayesian Information Criterion (BIC). Finally concluded that multivariant ARIMA $(2,0,0)$ model as best fitted model with $95 \%$ confidence interval on predicted values. [25]

\section{Tapak, L., Hamidi, O., Fathian, M., Karami, M. (2019). Comparative evaluation of time series models for predicting influenza outbreaks: application of influenza-like illness data from sentinel sites of healthcare centers in iran. BMC Research Notes, 12, 353.}

In this study researchers investigated the accuracy of support vector machine, artificial neural-network, and random-forest time series models in influenza like illness (ILI) modeling, outbreaks detection and evaluated through Root Mean Square Errors (RMSE), Mean Absolute Errors (MAE), and Intra-Class Correlation Coefficient (ICC) statistics. With $\mathrm{RMSE}=22.78, \mathrm{MAE}=14.99$ and $\mathrm{ICC}=0.88$ for random forest time series on test set. From this study we considered using error measures is an efficient way to evaluate the models. [26] 


\section{Chapter III METHODOLOGY}




\section{$\underline{\text { Study Design }}$}

The data source we selected was Missouri Telehealth Network (MTN) Show Me-ECHO data repository from iECHO and RedCap. Show Me-ECHO data comprise of 39797 observations (attendance) from 09/20/2014 (inception) - 10/20/2020 (data collection end date), includes 35 types of ECHO programs data. As of inclusion criteria, we considered data from 01/01/2015 - 12/31/2019 for time series analysis and excluded data from Oct 2014 - Dec 2014, (due to unavailability of data for the whole 2014) and data from Jan 2020

- Dec 2020, (because of COVID-19 pandemic there is more involvement of participants in topics related to pandemic (COVID-19, COVID-19 Kids, Moms \& Babies COVID) due to remote working, interest in current situation and also due to decrease in direct patient care involvement) which is inconsistent/inappropriate to compare with other years since we are predicting monthly attendance. We selected most widely used models ARIMA (Autoregressive Integrated Moving Average) and SMA (Simple Moving Average) from each Autoregressive and Moving Average forecasting algorithms for comparison of prediction values. As of evaluation of models, we followed scale-dependent measures like Mean Square Error (MSE), Mean Absolute Error (MAE) and measures based on percentage errors such as Mean Absolute Percentage Error (MAPE) which are widely used methods along with R-Square values and p-Value of both models.

Programming - Python (ADF test): Evaluation of initial data to test data stationarity, Excel: Both Simple Moving Average and ARIMA models on dataset for forecasting, Evaluating model fitness on data. 


\section{Data Resource Instruments/Tools}

RedCap: RedCap is a metadata driven electronic data capture web-based software which can be used for designing and processing of surveys, storing and mining of confidential multi-dimensional data. It is an exceptional secured clinical and translational research database workflow management system supported by NCRR grants and NIH [27, 28]. It was developed in 2004 [29] by an informatics team at Vanderbilt University to address using electronic data bases and to support multidisciplinary independent research environments which lacks effective IT integration in protocols. [30] Some features include Easy survey design (wide choice of question types, quality checks, limited layout capabilities), versatile survey taking options (open surveys with links, personal, schedules invitations, offline staff editing), few native data analysis capabilities (data export to excel, $\mathrm{R}, \mathrm{SAS}$, SPSS files).

iECHO: It is a wed based tool started in 2010 by University of New Mexico [UNM] to manage and inspect tele $\mathrm{ECHO}$ clinics about clinic performance by collecting data and serves as a resource provider for partners (collaborative organizations). It was designed to track and report tele ECHO program components, for iECHO informational storage includes program administrative data, attendance records for participants and facilitators, case presentation metrics, didactic presentations, program documents, and awarded $\mathrm{CME} / \mathrm{CEU} / \mathrm{CE}$ credits. The software is not meant to store any health information of individuals. [31] 


\section{Procedure}

\section{Figure 8: Data Observations \& Analysis Study Process}

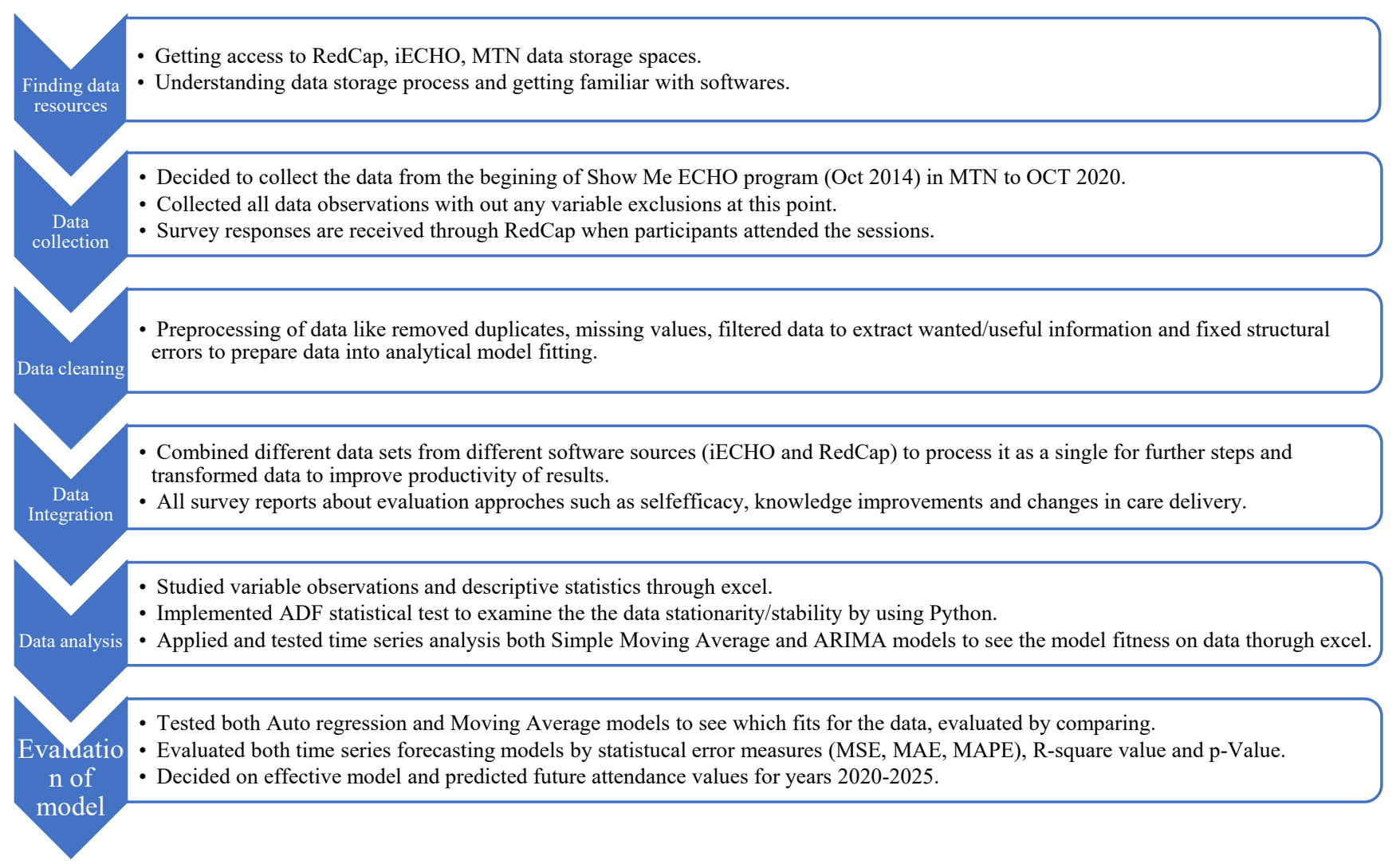




\section{Chapter IV RESULTS}




\section{Descriptive Analysis of Data}

We analyzed the raw data to get familiar with observations for further analysis and obtained various kinds of information such as number of ECHO sessions and topics that the organization is conducting, type of participants, participating organizations, along with that we observed elevations in ECHO programs and participants from inception in 2014 to current 2020.

Table 2: Show-Me ECHO Disease Variables

\begin{tabular}{|c|c|c|c|c|c|c|c|c|c|}
\hline \multirow[t]{2}{*}{ S.No } & \multirow[t]{2}{*}{ Topic } & \multirow[t]{2}{*}{ Start Date } & \multirow[t]{2}{*}{ Last Date } & \multirow{2}{*}{$\begin{array}{l}\text { Still in } \\
\text { Progres } \\
\mathrm{S}\end{array}$} & \multirow{2}{*}{$\begin{array}{l}\text { No. } \\
\text { Sessio } \\
\text { ns }\end{array}$} & \multirow{2}{*}{$\begin{array}{l}\text { Total } \\
\text { Observa } \\
\text { tions }\end{array}$} & \multicolumn{3}{|c|}{ Total count (Unique Individuals) } \\
\hline & & & & & & & $\begin{array}{l}\text { No. } \\
\text { Attendees }\end{array}$ & $\begin{array}{l}\text { No. } \\
\text { Facilitators }\end{array}$ & $\begin{array}{l}\text { No. } \\
\text { Counties } \\
\text { involved }\end{array}$ \\
\hline 1 & Asthma & $9 / 8 / 2015$ & $10 / 13 / 2020$ & Yes & 157 & 4910 & 825 & 27 & 61 \\
\hline 2 & ATTC & $9 / 26 / 2016$ & $1 / 10 / 2017$ & No & 7 & 48 & 10 & 10 & 3 \\
\hline 3 & Autism & $2 / 4 / 2015$ & $10 / 19 / 2020$ & Yes & 342 & 5440 & 751 & 64 & 80 \\
\hline 4 & $\begin{array}{l}\text { Certified Peer } \\
\text { Specialist }\end{array}$ & $2 / 5 / 2020$ & $10 / 7 / 2020$ & Yes & 17 & 468 & 111 & 6 & 34 \\
\hline 5 & Child Psych & $1 / 10 / 2017$ & $10 / 9 / 2020$ & Yes & 45 & 1141 & 295 & 10 & 47 \\
\hline 6 & CHW & $1 / 10 / 2017$ & $10 / 6 / 2020$ & Yes & 52 & 2642 & 378 & 13 & 63 \\
\hline 7 & COVID 19 & $3 / 23 / 2020$ & $10 / 12 / 2020$ & Yes & 28 & 5890 & 1050 & 12 & 97 \\
\hline 8 & $\begin{array}{l}\text { COVID } \\
19 \& \text { Kids }\end{array}$ & $9 / 17 / 2020$ & $10 / 15 / 2020$ & Yes & 5 & 646 & 311 & 10 & 64 \\
\hline 9 & Crown & $2 / 28 / 2019$ & $12 / 12 / 2019$ & No & 17 & 215 & 48 & 10 & 18 \\
\hline 10 & Dermatology & $11 / 20 / 2015$ & $10 / 16 / 2020$ & Yes & 110 & 2133 & 254 & 14 & 38 \\
\hline 11 & $\begin{array}{l}\text { Developmental } \\
\text { Disabilities }\end{array}$ & $8 / 8 / 2019$ & $10 / 8 / 2020$ & Yes & 23 & 401 & 156 & 8 & 39 \\
\hline 12 & Endocrinology & $8 / 20 / 2015$ & $12 / 13 / 2016$ & No & 42 & 526 & 115 & 7 & 18 \\
\hline 13 & $\begin{array}{l}\text { Foot } \\
\text { Preservation }\end{array}$ & $9 / 2 / 2020$ & $10 / 7 / 2020$ & Yes & 2 & 28 & 11 & 9 & 9 \\
\hline 14 & Genetics & $2 / 14 / 2019$ & $5 / 23 / 2019$ & No & 2 & 5 & 5 & 0 & 4 \\
\hline 15 & Head Start & $1 / 15 / 2020$ & $9 / 16 / 2020$ & Yes & 6 & 129 & 54 & 9 & 17 \\
\hline 16 & $\begin{array}{l}\text { Healthcare } \\
\text { Ethics }\end{array}$ & $1 / 10 / 2017$ & $6 / 13 / 2019$ & No & 18 & 311 & 89 & 9 & 19 \\
\hline 17 & HIV & $11 / 8 / 2018$ & $10 / 8 / 2020$ & Yes & 11 & 238 & 78 & 10 & 9 \\
\hline 18 & Hope & $2 / 5 / 2019$ & $12 / 17 / 2019$ & No & 19 & 257 & 49 & 13 & 11 \\
\hline 19 & Hypertension & $10 / 28 / 2019$ & $10 / 12 / 2020$ & Yes & 11 & 273 & 82 & 10 & 30 \\
\hline 20 & Kidney Disease & $10 / 3 / 2019$ & $8 / 15 / 2019$ & Yes & 26 & 605 & 122 & 13 & 38 \\
\hline 21 & $\begin{array}{l}\text { Missouri Moms } \\
\& \text { Babies }\end{array}$ & $6 / 24 / 2020$ & $10 / 14 / 2020$ & Yes & 8 & 298 & 110 & 13 & 28 \\
\hline
\end{tabular}




\begin{tabular}{|c|c|c|c|c|c|c|c|c|c|}
\hline 22 & MTSS & $4 / 17 / 2018$ & $2 / 27 / 2020$ & No & 18 & 315 & 128 & 9 & 21 \\
\hline 23 & NAS & $2 / 7 / 2019$ & $10 / 3 / 2019$ & No & 17 & 216 & 61 & 9 & 17 \\
\hline 24 & $\begin{array}{l}\text { Nurse } \\
\text { Education }\end{array}$ & $1 / 9 / 2019$ & $4 / 22 / 2020$ & No & 21 & 1550 & 541 & 3 & 103 \\
\hline 25 & Oral Health & $2 / 13 / 2019$ & $10 / 14 / 2020$ & Yes & 20 & 373 & 109 & 11 & 31 \\
\hline 26 & OUD & $1 / 10 / 2017$ & $10 / 9 / 2020$ & Yes & 52 & 1178 & 366 & 12 & 51 \\
\hline 27 & $\begin{array}{l}\text { Pain } \\
\text { Management }\end{array}$ & $11 / 16 / 2014$ & $10 / 8 / 2020$ & Yes & 92 & 2344 & 433 & 17 & 44 \\
\hline 28 & Pediatric Sleep & $8 / 10 / 2020$ & $10 / 12 / 2020$ & Yes & 7 & 108 & 33 & 6 & 15 \\
\hline 29 & PrEP & $8 / 7 / 2019$ & $9 / 18 / 2019$ & No & 4 & 5 & 1 & 4 & 4 \\
\hline 30 & Rural Veterans & $9 / 5 / 2018$ & $7 / 23 / 2019$ & No & 19 & 239 & 48 & 7 & 20 \\
\hline 31 & $\begin{array}{l}\text { SEMO } \\
\text { Diabetes }\end{array}$ & $9 / 3 / 2019$ & $5 / 19 / 2020$ & No & 17 & 395 & 88 & 9 & 28 \\
\hline 32 & Telemedicine & $4 / 14 / 2020$ & $10 / 13 / 2020$ & Yes & 21 & 503 & 152 & 3 & 40 \\
\hline 33 & $\begin{array}{l}\text { Trauma } \\
\text { Informed } \\
\text { Schools }\end{array}$ & $11 / 19 / 2019$ & $9 / 8 / 2020$ & Yes & 12 & 341 & 171 & 9 & 43 \\
\hline 34 & $\begin{array}{l}\text { Urban } \\
\text { Dermatology }\end{array}$ & $2 / 12 / 2020$ & $5 / 13 / 2020$ & No & 4 & 35 & 19 & 2 & 6 \\
\hline 35 & $\begin{array}{l}\text { Viral Hepatitis } \\
\text { \& Fattyliver }\end{array}$ & $1 / 20 / 2016$ & $10 / 16 / 2020$ & Yes & 67 & 980 & 147 & 17 & 33 \\
\hline
\end{tabular}

MTN Show me ECHO program has 35 program topics started on differed dates from Oct' 2014 - Dec' 2020. Table 2: shows individual details about specific program such as number of sessions conducted, number of attendees, facilitators and counties involved.

\section{Comparison study Results -}

Tested both SMA and ARIMA on actual data and calculated prediction values for actual values $(2015$ - 2019) and to select appropriate time series analysis type for forecasting, compared R-square value and p-value through basic regression test and error scale measures like Mean Square Error (MSE), Mean Absolute Error (MAE) and measures based on percentage errors such as Mean Absolute Percentage Error (MAPE) were used due to their high efficiency. 
Figure 9: Comparison of SMA and ARIMA forecasting models (2015 - 2019)

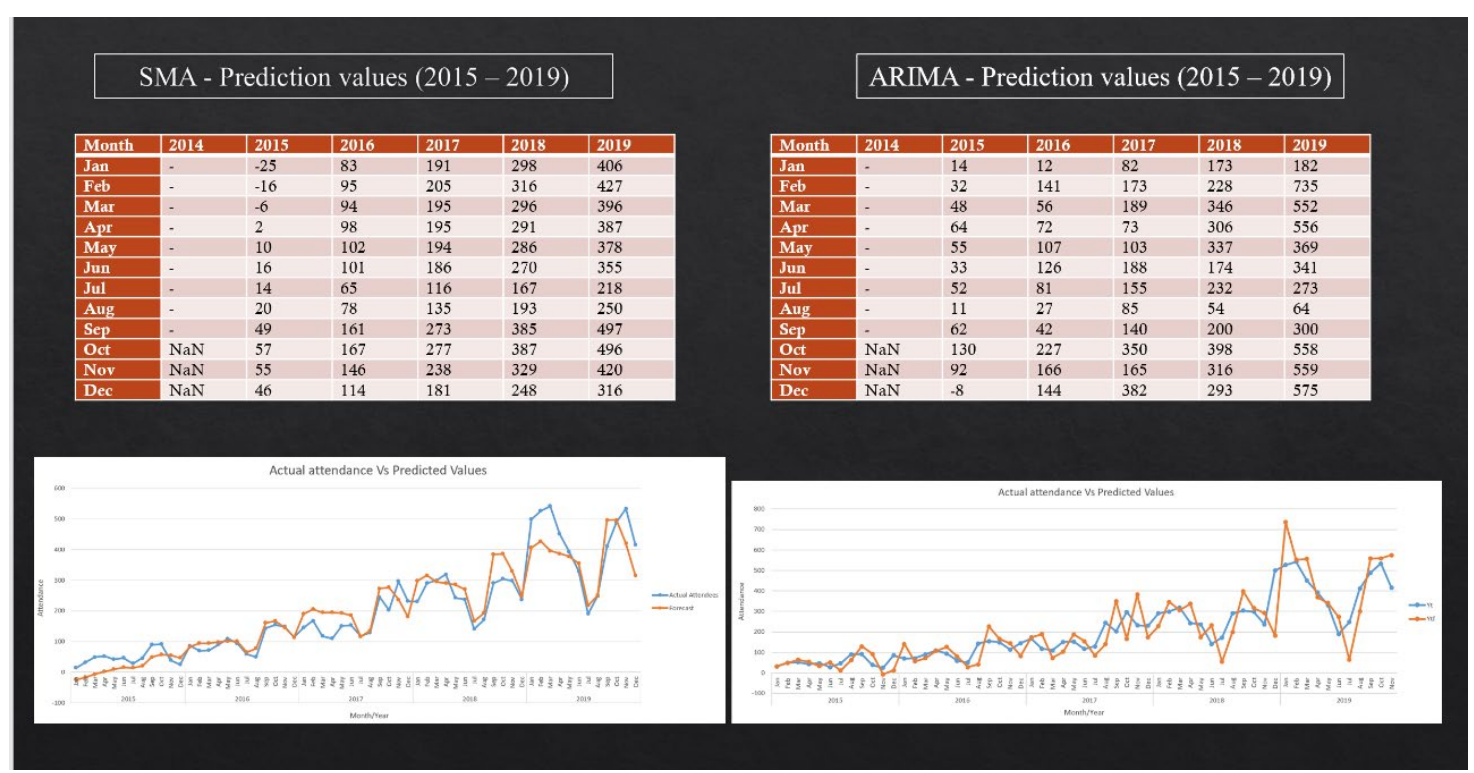

Table 3: Comparison of SMA and ARIMA forecasting models (2015 - 2019)

\begin{tabular}{|c|c|c|l|}
\hline Error tests & SMA Values & ARIMA Values & \multicolumn{1}{|c|}{ Reference Values } \\
\hline MAE/MAD & 38.90 & 61.82 & 0 to $\infty$ (Lower values are better) \\
\hline MSE & 2552.15 & 7198.88 & $-10,000-+10,000$ \\
\hline MAPE & $32.9 \%$ & $37.7 \%$ & $\begin{array}{l}<10 \% \text { is Excellent, } \\
<20 \% \text { is Very Good }\end{array}$ \\
\hline R-square value & 0.878 & 0.805 & \\
\hline p-value & $3.36 \mathrm{E}-28$ & $6.25 \mathrm{E}-22$ & \\
\hline
\end{tabular}

So, we selected SMA model with lower error values, MAE - 38.9, MSE - 2552.15, MAPE $-32.9 \%$, p- value: $3.36 \mathrm{E}-28$, and higher $\mathrm{R}$ - square: $87 \%$ for forecasting, Where ARIMA model was with higher error values MAE - 61.8, MSE - 7198.88, MAPE - 37.7\%, pvalue: $6.25 \mathrm{E}-22$, and lower $\mathrm{R}$ - square: $80 \%$.

\section{SMA Time Series Forecasting Values -}

Predicted attendance from January 2020 - December 2025 using Simple Moving Average which was proved as a better prediction model for the current dataset.

Table 4: Future Predicted Attendance (Simple Moving Average Forecasting) (2020-2025) 


\begin{tabular}{|l|l|l|l|l|l|l|}
\hline Month & $\mathbf{2 0 2 0}$ & $\mathbf{2 0 2 1}$ & $\mathbf{2 0 2 2}$ & $\mathbf{2 0 2 3}$ & $\mathbf{2 0 2 4}$ & $\mathbf{2 0 2 5}$ \\
\hline Jan & 514 & 621 & 729 & 837 & 945 & 1052 \\
\hline Feb & 538 & 649 & 760 & 871 & 981 & 1092 \\
\hline Mar & 497 & 597 & 698 & 799 & 899 & 1000 \\
\hline Apr & 484 & 580 & 676 & 773 & 869 & 965 \\
\hline May & 470 & 562 & 654 & 746 & 839 & 931 \\
\hline Jun & 440 & 525 & 610 & 694 & 779 & 864 \\
\hline Jul & 269 & 320 & 371 & 422 & 473 & 524 \\
\hline Aug & 308 & 366 & 423 & 481 & 538 & 596 \\
\hline Sep & 608 & 720 & 832 & 944 & 1056 & 1168 \\
\hline Oct & 606 & 716 & 826 & 936 & 1045 & 1155 \\
\hline Nov & 511 & 603 & 694 & 785 & 876 & 968 \\
\hline Dec & 383 & 450 & 518 & 585 & 652 & 720 \\
\hline
\end{tabular}

Figure 10: Attendance both Actual Past (2015-2019) and Future Predicted (2020-2025)

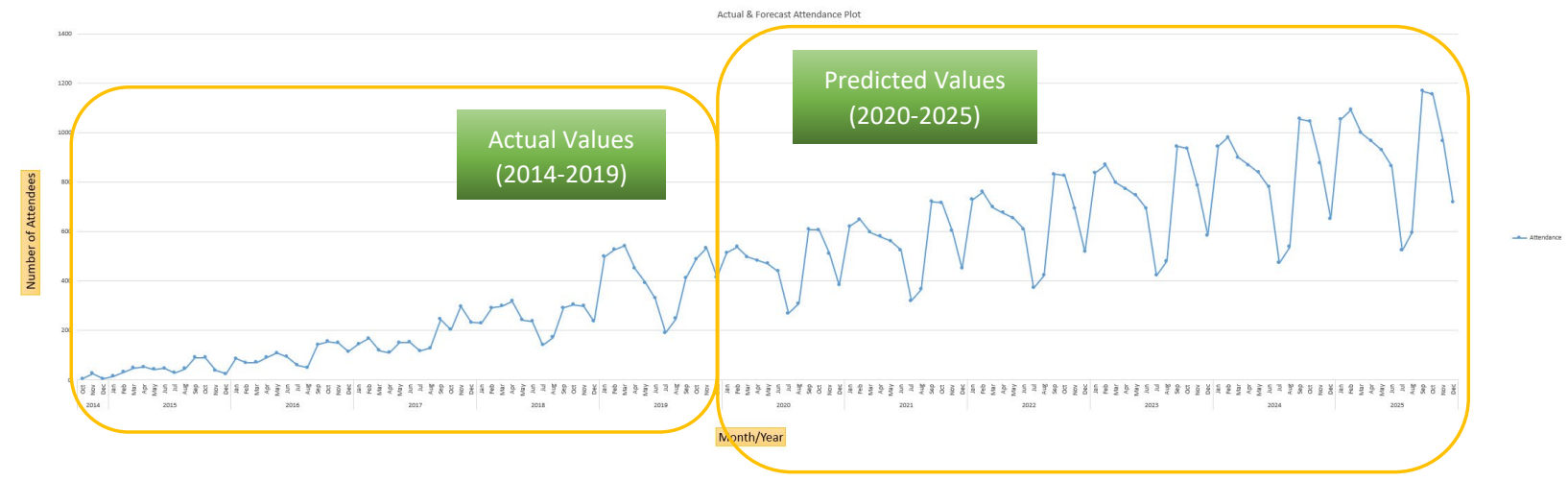

The findings from forecasting step indicates that in 2019 , the attendance range was 250550 , where in 2025 it is increased to 530-1170; this says that telehealth attendance will be doubled in the next five years. 


\section{Chapter V CONCLUSION}


The main purpose of this study is to prove that telemedicine ECHO project progression and health professional's participation will observe an uptrend in the future. To support this statement, during the early stages of the study we were interested in predicting the future values and see the trend in participation of training programs.

We identified that SMA model is the best forecasting technique compared with ARIMA model for datasets with independent variables and non-stationary trends. There will be an increase in care providers participation in telehealth related programs includes educational, training programs where the development and utilization of telemedicine services is important, as these services allow health care professionals to continue in providing highquality healthcare.

As further and prospective use of current study statements, this type of forecasting analysis helps to identify irregularities, systematic variations in data series including seasonality, data trends, growth rates and cyclic patterns. [32] By considering limited independent quantitative data in preliminary analysis this method is useful to predict future census in hospital units like in emergency departments to correspond with proper utilization measures by anticipating cases ahead of time [25, 33], in quality improvement programs, like predicting intensive care unit readmissions and needed facility arrangements, like improving appointment scheduling. [36] Also useful in analyzing Disease outbreaks and infectious disease surveillance by using existed data in predicting disease patterns helps in minimizing disease impact with early preventive measure follow ups, population health messaging and escalating clinicians' awareness for timely treatment and diagnosis. [26, 33, 34, 35] 
While the researchers still agree to the findings and conclusions, there are some limitations in the study like - 1.) data does not have any dependent variables, 2.) data is not stable and sample size is very small with only 60 observations. The availability of long time series data for the study of different models is very important in developing efficient forecasting system. [22], and limitation 3.) data contains some ECHOs which are ended before Dec 2020. 


\section{REFERENCES}


1. Project ECHO. (n.d.). Retrieved May 5, 2021, from https://hsc.unm.edu/echo/

2. Komaromy, M., Ceballos, V., Zurawski, A., Bodenheimer, T., Thom, D. H., \& Arora, S. (2018). Extension for Community Healthcare Outcomes (ECHO): A new model for community health worker training and support. Journal of Public Health Policy, 39(2), 203-216. https://doi.org/10.1057/s41271-017-0114-8

3. Arora, S., Thornton, K., Murata, G., Deming, P., Kalishman, S., Dion, D., Parish, B., Burke, T., Pak, W., Dunkelberg, J., Kistin, M., Brown, J., Jenkusky, S., Komaromy, M., \& Qualls, C. (2011). Outcomes of treatment for hepatitis C virus infection by primary care providers. The New England Journal of Medicine, 364(23), 2199-2207. https://doi.org/10.1056/NEJMoa1009370

4. Katzman, J. G., Galloway, K., Olivas, C., McCoy-Stafford, K., Duhigg, D., Comerci, G., Kalishman, S., Buckenmaier, C. C., McGhee, L., Joltes, K., Bradford, A., Shelley, B., Hernandez, J., \& Arora, S. (2016). Expanding Health Care Access Through Education: Dissemination and Implementation of the ECHO Model. Military Medicine, 181(3), 227-235. https://doi.org/10.7205/MILMED-D-15$\underline{00044}$

5. Carlin, L., Zhao, J., Dubin, R., Taenzer, P., Sidrak, H., \& Furlan, A. (2018). Project ECHO Telementoring Intervention for Managing Chronic Pain in Primary Care: Insights from a Qualitative Study. Pain Medicine (Malden, Mass.), 19(6), 11401146. https://doi.org/10.1093/pm/pnx233

6. Frank, J. W., Carey, E. P., Fagan, K. M., Aron, D. C., Todd-Stenberg, J., Moore, B. A., Kerns, R. D., Au, D. H., Ho, P. M., \& Kirsh, S. R. (2015). Evaluation of a telementoring intervention for pain management in the Veterans Health 
Administration. Pain Medicine (Malden, Mass.), 16(6), 1090-1100. https://doi.org/10.1111/pme.12715

7. De Witt Jansen, B., Brazil, K., Passmore, P., Buchanan, H., Maxwell, D., McIlfatrick, S. J., Morgan, S. M., Watson, M., \& Parsons, C. (2018). Evaluation of the impact of telementoring using $\mathrm{ECHO} \odot$ technology on healthcare professionals' knowledge and self-efficacy in assessing and managing pain for people with advanced dementia nearing the end of life. BMC Health Services Research, 18(1), 228. https://doi.org/10.1186/s12913-018-3032-y

8. Arora, S., Kalishman, S., Dion, D., Som, D., Thornton, K., Bankhurst, A., Boyle, J., Harkins, M., Moseley, K., Murata, G., Komaramy, M., Katzman, J., Colleran, K., Deming, P., \& Yutzy, S. (2011). Partnering urban academic medical centers and rural primary care clinicians to provide complex chronic disease care. Health Affairs (Project $\quad$ Hope), $\quad 30(6), \quad$ 1176-1184. https://doi.org/10.1377/hlthaff.2011.0278

9. Hubs \& Programs. (n.d.). Retrieved December 18, 2020, from https:/hsc.unm.edu/echo/data-marketplace/interactive-dashboards/

10. Lewiecki, E. M., \& Rochelle, R. (2019). Project ECHO: Telehealth to Expand Capacity to Deliver Best Practice Medical Care. Rheumatic Diseases Clinics of North America, 45(2), 303-314. https://doi.org/10.1016/j.rdc.2019.01.003

11. Dearing, J. W. (n.d.). Project ECHO: Review and Research Agenda. 47. http://www.diffusionassociates.com/wp-content/uploads/2019/09/echo.pdf

12. Saunders, R. P., Evans, M. H., \& Joshi, P. (2005). Developing a process-evaluation plan for assessing health promotion program implementation: A how-to guide. 
Health Promotion $\quad$ Practice, 6(2), 134-147. https://doi.org/10.1177/1524839904273387

13. White, W. L. (2004). Process Evaluation for Public Health Interventions and Research: Process Evaluation for Public Health Interventions and Research; Allan Steckler, Laura Linnan (Eds.); Jossey-Bass, San Francisco, CA, 2002, 400 pages. Evaluation and Program Planning, 27(1), 118-119. https://doi.org/10.1016/j.evalprogplan.2003.09.006

14. Friedman, M. (n.d.). Results-Based Accountability Producing Measurable Improvements for Customers and Communities. 8 . https://www.oecd.org/site/progresskorea/44120813.pdf

15. Drummond MF, O'Brien B, Stoddart GL, Torrance GW. (1997). Methods for the Economic Evaluation of Health Care Programs, 2nd ed. Oxford Medical Publications, Oxford University Press, New York.

16. Time Series. (2008). In the Concise Encyclopedia of Statistics (pp. 536-539). Springer. https://doi.org/10.1007/978-0-387-32833-1_401

17. Peixeiro, M. (2021, April 18). The Complete Guide to Time Series Analysis and Forecasting. Medium. https://towardsdatascience.com/the-complete-guide-totime-series-analysis-and-forecasting-70d476bfe 775

18. How to Choose the Right Forecasting Technique. (n.d.). Retrieved May 5, 2021, from https://hbr.org/1971/07/how-to-choose-the-right-forecasting-technique

19. Côté, M. J., \& Tucker, S. L. (2001). Four methodologies to improve healthcare demand forecasting. Healthcare Financial Management: Journal of the Healthcare Financial Management Association, 55(5), 54-58. 
20. Zoran Ivanovski, Ace Milenkovski, and Zoran Narasanov. 2018. Time Series Forecasting Using a Moving Average Model for Extrapolation of Number of Tourist. UTMS Journal of Economics 9 (2): 121-132. https://www.researchgate.net/publication/329714218

21. Aryee, G., Kwarteng, E., Essuman, R., Nkansa Agyei, A., Kudzawu, S., Djagbletey, R., Owusu Darkwa, E., Forson, A. (2018). Estimating the incidence of tuberculosis cases reported at a tertiary hospital in Ghana: a time series model approach. BMC Public Health, 18, 1292. https://doi.org/10.1186/s12889-018-6221-z

22. Briet, O. J., Vounatsou, P., Gunawardena, D. M., Galappaththy, G. N., Amerasinghe, P. H. (2008). Models for short term malaria prediction in Sri Lanka. Malaria Journal, 7, 76. http://www.malariajournal.com/content/7/1/76

23. Loha, E., Lindtjorn, B. (2010). Model variations in predicting incidence of plasmodium falciparum malaria using 1998-2007 morbidity and meteorological data from south Ethiopia. Malaria Journal, 9, 166. http://www.malariajournal.com/content/9/1/166

24. Mai, Q., Aboagye-Sarfo, P., Sanfilippo, F. M., Preen, D. B., Fatovich, D. M. (2015). Predicting the number of emergency department presentations in western Australia: a population-based time series analysis. Emergency Medicine Australasia, 27, 1621. https://pubmed.ncbi.nlm.nih.gov/25583296/

25. N'gattia, A. K., Coulibaly, D., Nzussouo, N. T., Kadjo, H. A., Cherif, D., Traore, Y., Kouakou, B. K., Kouassi, P. D., Ekra, K. D., Dagnan, N. S., Williams, T., Tiembre, I. (2016). Effects of climatological parameters in modeling and 
forecasting seasonal influenza transmission in Abidjan, cote d'ivoire. BMC Public Health, 16, 972. https://www.ncbi.nlm.nih.gov/pmc/articles/PMC5022141/

26. Tapak, L., Hamidi, O., Fathian, M., Karami, M. (2019). Comparative evaluation of time series models for predicting influenza outbreaks: application of influenza-like illness data from sentinel sites of healthcare centers in iran. BMC Research Notes, 12, 353. https://doi.org/10.1186/s13104-019-4393-y

$\begin{array}{llll}\text { 27. REDCap. } & \text { (2021). } & \text { In } & \text { Wikipedia. }\end{array}$ https://en.wikipedia.org/w/index.php?title=REDCap\&oldid=1023904087

28. Software - REDCap. (n.d.). Retrieved May 21, 2021, from https://projectredcap.org/software/

29. Harris, P. A., Taylor, R., Thielke, R., Payne, J., Gonzalez, N., \& Conde, J. G. (2009). Research Electronic Data Capture (REDCap) - A metadata-driven methodology and workflow process for providing translational research informatics support. Journal of Biomedical Informatics, 42(2), 377-381. https://doi.org/10.1016/j.jbi.2008.08.010

30. Zerhouni, E. A. (2003). A New Vision for the National Institutes of Health. Journal of Biomedicine and Biotechnology, 2003(3), 159-160. https://doi.org/10.1155/S1110724303306023

31. IECHO. (n.d.). Retrieved May 21, 2021, from https://iecho.unm.edu/

32. How to Choose the Right Forecasting Technique. (n.d.). Retrieved May 21, 2021, from https://hbr.org/1971/07/how-to-choose-the-right-forecasting-technique

33. Capan, M., Hoover, S., Jackson, E. V., Paul, D., \& Locke, R. (2016). Time Series Analysis for Forecasting Hospital Census: Application to the Neonatal Intensive 
Care Unit. Applied Clinical Informatics, 7(2), 275-289. https://doi.org/10.4338/ACI-2015-09-RA-0127

34. Reis, B. Y., \& Mandl, K. D. (2003). Time series modeling for syndromic surveillance. BMC Medical Informatics and Decision Making, 3, 2. https://doi.org/10.1186/1472-6947-3-2

35. Brillman, J. C., Burr, T., Forslund, D., Joyce, E., Picard, R., \& Umland, E. (2005). Modeling emergency department visit patterns for infectious disease complaints: Results and application to disease surveillance. BMC Medical Informatics and Decision Making, 5, 4. https://doi.org/10.1186/1472-6947-5-4

36. Platforms of Intelligence for healthcare providers and payers: The path to personalization and efficient operations. (2020, September 17). ITC Infotech. https://www.itcinfotech.com/blog/platforms-of-intelligence-for-healthcareproviders-and-payers/ 
APPENDIX 


\section{MTN ECHO Data specific details -}

\section{ECHO Participant Type}

\begin{tabular}{|l|l|l|l|l|l|l|l|}
\hline & $\mathbf{2 0 1 4}$ & $\mathbf{2 0 1 5}$ & $\mathbf{2 0 1 6}$ & $\mathbf{2 0 1 7}$ & $\mathbf{2 0 1 8}$ & $\mathbf{2 0 1 9}$ & $\mathbf{2 0 2 0}$ \\
\hline Physician (MD, DO) & 3 & 68 & 138 & 171 & 180 & 241 & 370 \\
\hline Clinical Pharmacist (PharmD) & 0 & 3 & 6 & 13 & 18 & 18 & 33 \\
\hline Physician Assistant (PA, MHS) & 0 & 3 & 5 & 7 & 8 & 16 & 9 \\
\hline Advanced Practice Nurse (NP, CRNA, CNM, CNS, etc) & 1 & 12 & 31 & 31 & 35 & 71 & 146 \\
\hline Registered Nurse (RN, BSN) & 4 & 29 & 46 & 101 & 111 & 549 & 742 \\
\hline Licensed Practical Nurse (LPN) & 3 & 9 & 25 & 18 & 16 & 110 & 87 \\
\hline Family Nurse Practitioner (FNP) & 1 & 8 & 13 & 9 & 12 & 21 & 41 \\
\hline Medical Assistant (MA, CMA) & 1 & 4 & 14 & 19 & 25 & 34 & 39 \\
\hline Certified Nursing Assistant (CAN) & 0 & 0 & 0 & 0 & 0 & 0 & 0 \\
\hline Registered Pharmacist (RPh) & 0 & 3 & 2 & 1 & 1 & 2 & 0 \\
\hline Registered Dietitian (RD) & 1 & 1 & 5 & 5 & 0 & 4 & 8 \\
\hline Community Health Worker/Representative (CHW/CHR) & 0 & 0 & 3 & 28 & 58 & 69 & 74 \\
\hline $\begin{array}{l}\text { Mental/Behavioral Health Professional (non-physician: LMHC, } \\
\text { LCSW, LPCC, etc) }\end{array}$ & 1 & 11 & 31 & 44 & 45 & 67 & 95 \\
\hline Certified Health Care Manager (FACHE) & 0 & 0 & 0 & 0 & 0 & 0 & 0 \\
\hline Registered Health Information Technician (RHIT) & 0 & 0 & 0 & 0 & 0 & 0 & 1 \\
\hline Case Manager & 0 & 0 & 0 & 0 & 0 & 0 & 0 \\
\hline Other & 11 & 101 & 255 & 487 & 721 & 919 & 1305 \\
\hline
\end{tabular}

\section{ECHO Participant Type}

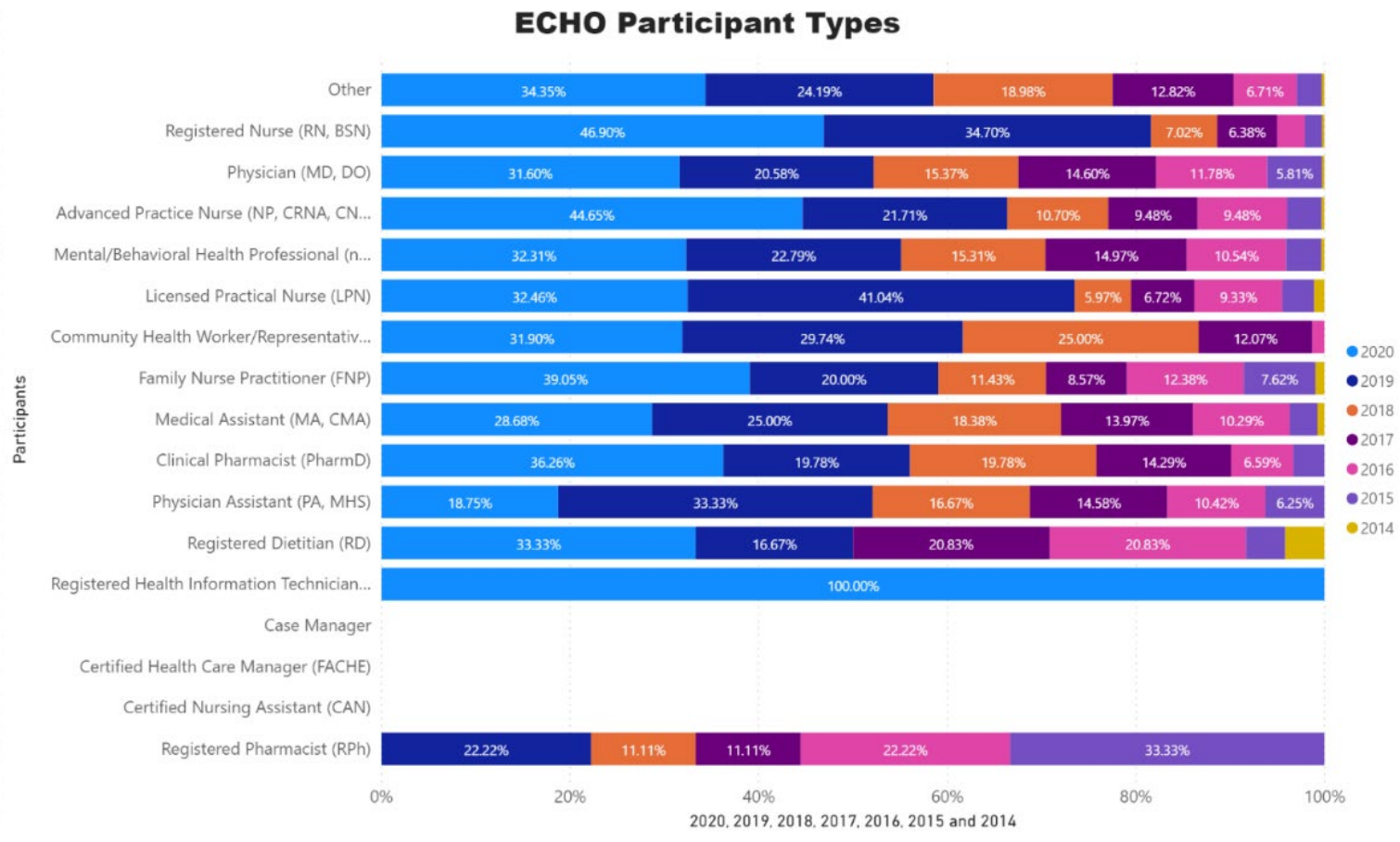

When it comes to participant category "Nursing professionals" (registered nurses, advanced practice nurses, etc..) are majorly involved in ECHO sessions compared to other types starting from inception. 
ECHO Participant Variables

\begin{tabular}{|c|c|c|c|c|c|c|}
\hline Year & $\begin{array}{c}\text { No. of Individual } \\
\text { Attendees }\end{array}$ & $\begin{array}{l}\text { No. of Individual } \\
\text { Facilitators }\end{array}$ & Grand Total & $\begin{array}{l}\text { total times } \\
\text { (attendees) }\end{array}$ & $\begin{array}{l}\text { total times } \\
\text { (facilitators) }\end{array}$ & Grand Total \\
\hline 2014 & 26 & 6 & 32 & 36 & 14 & 50 \\
\hline 2015 & 252 & 34 & 286 & 757 & 302 & 1059 \\
\hline 2016 & 574 & 61 & 635 & 1816 & 913 & 2729 \\
\hline 2017 & 934 & 104 & 1038 & 2882 & 1156 & 4038 \\
\hline 2018 & 1230 & 132 & 1362 & 4443 & 1575 & 6018 \\
\hline 2019 & 2121 & 233 & 2354 & 7033 & 2178 & 9211 \\
\hline 2020 & 2950 & 259 & 3209 & 14156 & 2477 & 16633 \\
\hline
\end{tabular}

\section{ECHO Participant Variables}

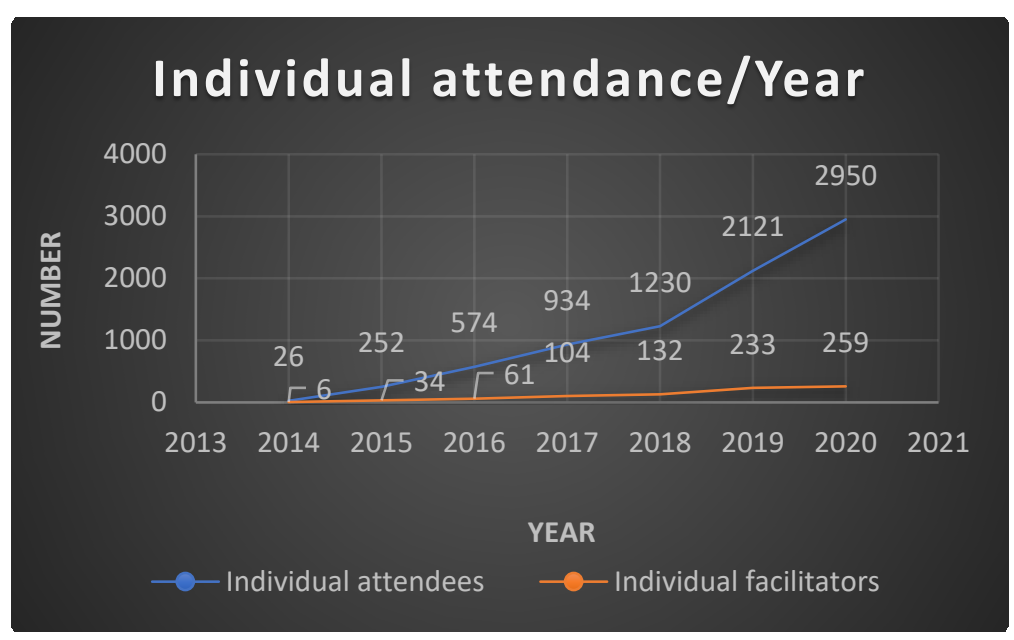

The number of attendees and facilitators were constantly increasing from $2014-2020$, as number of attendees increased from 26 to 2950 and number of facilitators increased from 6 to 259 .

\section{Number of Participating ECHO Organizations in Show-Me ECHO}

\begin{tabular}{|c|c|}
\hline Year & $\begin{array}{c}\text { No. of Participating } \\
\text { Organizations }\end{array}$ \\
\hline 2014 & 3 \\
\hline 2015 & 60 \\
\hline 2016 & 148 \\
\hline 2017 & 192 \\
\hline 2018 & 293 \\
\hline 2019 & 414 \\
\hline 2020 & 436 \\
\hline
\end{tabular}


Number of Participating ECHO Organizations in Show-Me ECHO

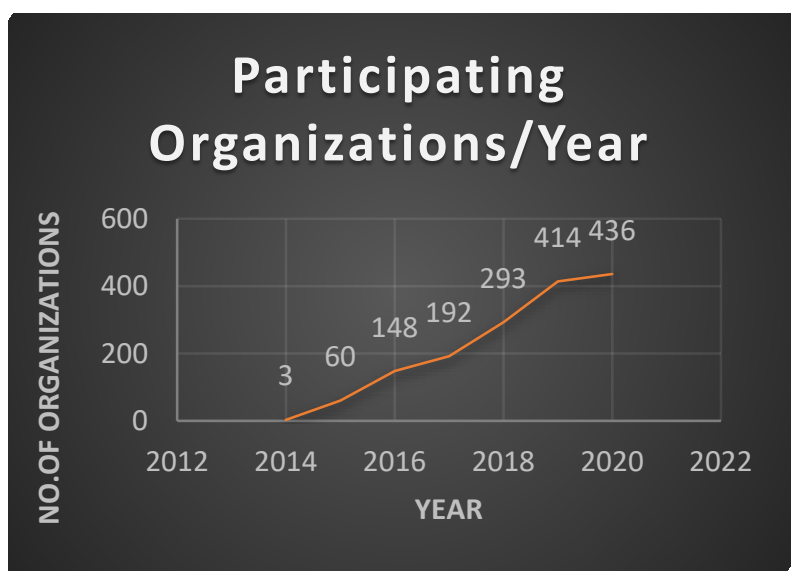

Number of participating organizations per year increased from 3 to 436 from inception to 2020.

Type of ECHO

\begin{tabular}{|c|c|c|c|}
\hline Year & In person (No. of Participants) & Audio (No. of Participants) & Video (No. of Participants) \\
\hline 2014 & 22 & 0 & 38 \\
\hline 2015 & 349 & 32 & 625 \\
\hline 2016 & 718 & 115 & 1390 \\
\hline 2017 & 547 & 177 & 2616 \\
\hline 2018 & 749 & 230 & 4343 \\
\hline 2019 & 706 & 667 & 6893 \\
\hline 2020 & 229 & 56 & 14969 \\
\hline
\end{tabular}

\section{Type of ECHO}

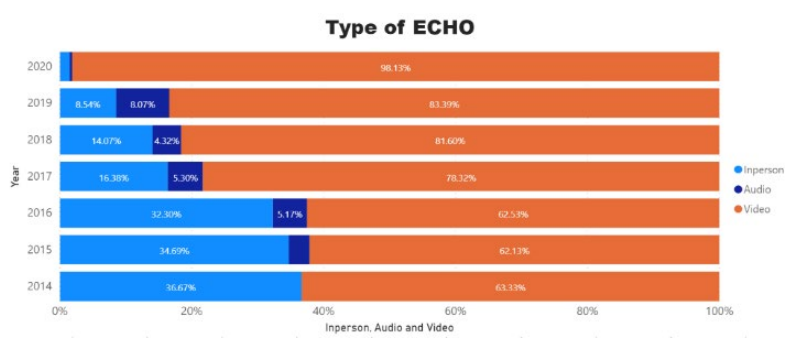

Starting from 2014, ECHO programs have both in-person and video sessions, but video sessions are more compared to in-person or audio because the actual purpose of telemedicine/telehealth programs is to bring people from distance and underserved areas for participation in training, educational programs. 
Number of Presentations and Presenters

\begin{tabular}{|c|c|c|}
\hline Year & Presenters & Presentations \\
\hline 2014 & 1 & 2 \\
\hline 2015 & 37 & 93 \\
\hline 2016 & 76 & 252 \\
\hline 2017 & 102 & 397 \\
\hline 2018 & 148 & 451 \\
\hline 2019 & 205 & 493 \\
\hline 2020 & 193 & 355 \\
\hline
\end{tabular}

\section{Number of Presentations and Presenters}

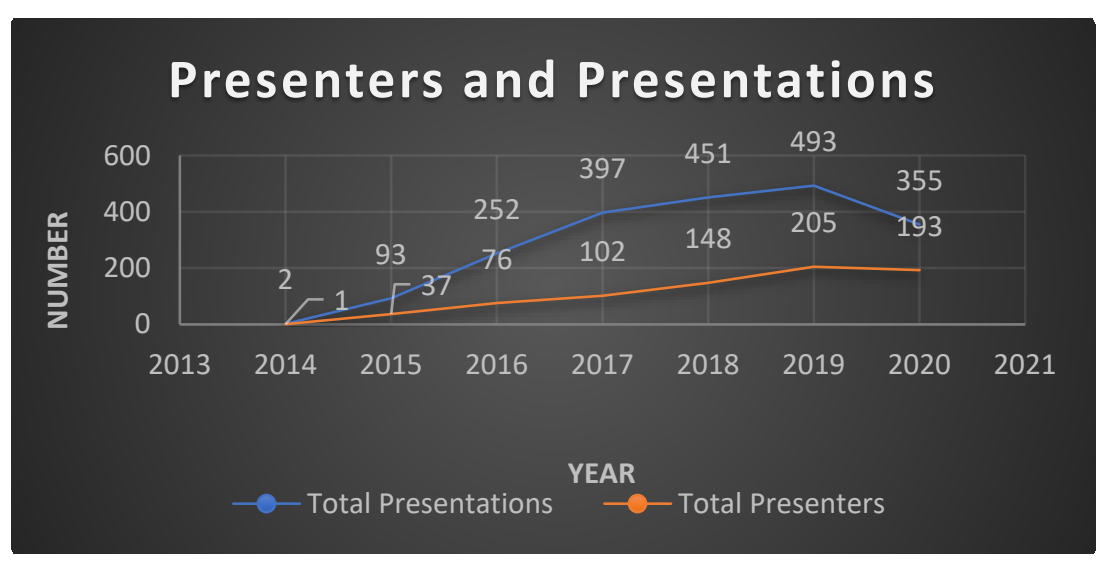

Number of presenters and presentations also got increased from 2014 to 2019 due to increase in attendance and sessions. But here we can observe decline in number for the year 2020, because of the unprecedent situations like COVID-19 pandemic, new ECHO sessions were started focusing on COVID topics. So, number of participants decreased in several other ECHO sessions and increased for COVID related ECHO programs.

\section{Counties' Involvement across Missouri state}

Involvement of Counties across Missouri

\begin{tabular}{|c|c|}
\hline Year & $\begin{array}{c}\text { Participants/Healthcare center } \\
\text { counties (across Missouri) }\end{array}$ \\
\hline 2014 & 8 \\
\hline 2015 & 40 \\
\hline 2016 & 52 \\
\hline 2017 & 66 \\
\hline 2018 & 72 \\
\hline 2019 & 102 \\
\hline 2020 & 108 \\
\hline
\end{tabular}



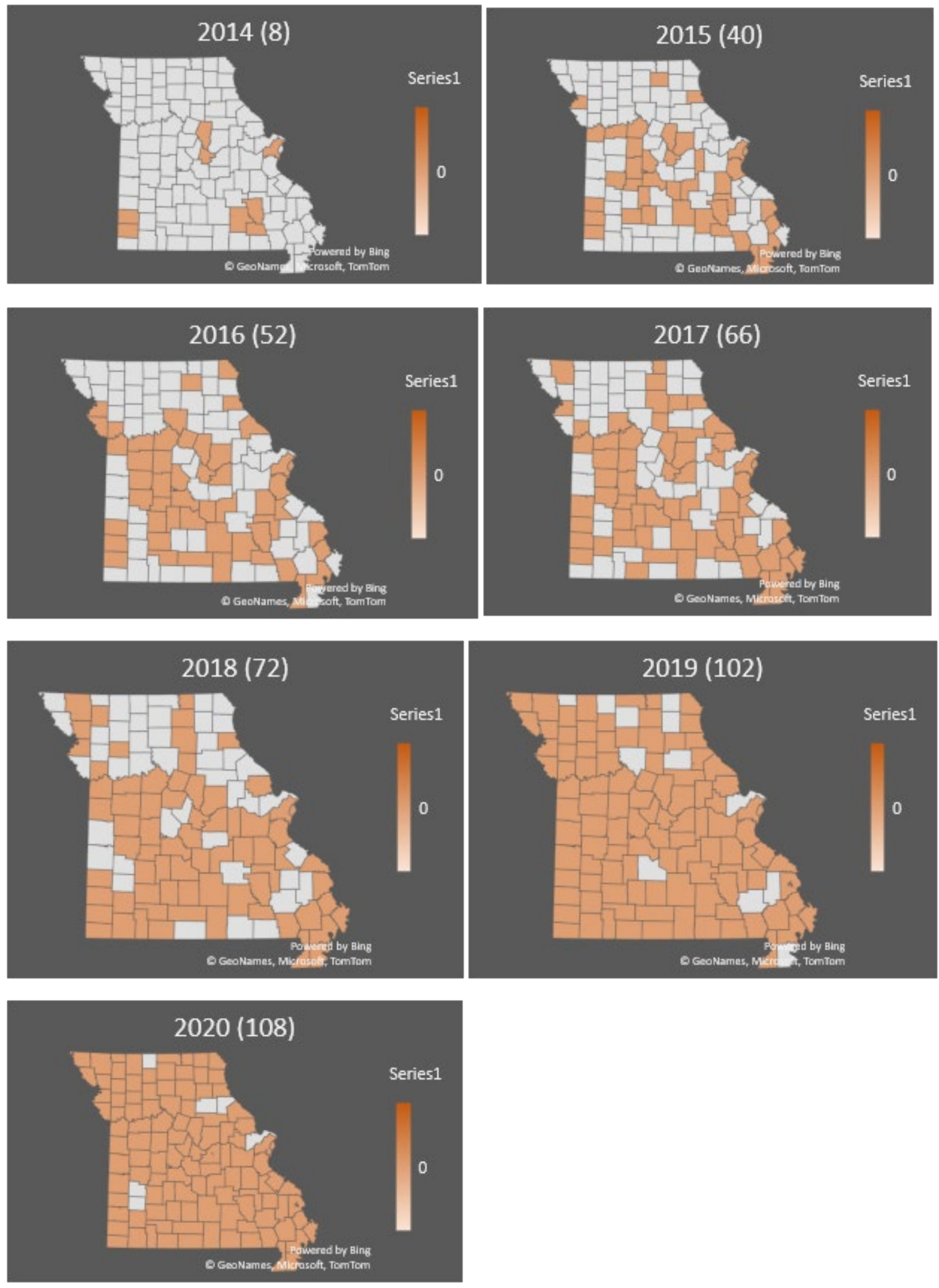
The number of counties involved in ECHO programs also increased from 8 in 2014 to 108 in 2020 .

\section{Detailed SMA \& ARIMA calculation steps -}

\section{Testing stationarity of Data: (Augmented Dickey-Fuller test/Python)}

Monthly Actual Attendance: (2015-2019)

\begin{tabular}{|l|l|l|l|l|l|l|}
\hline Month & $\mathbf{2 0 1 4}$ & $\mathbf{2 0 1 5}$ & $\mathbf{2 0 1 6}$ & $\mathbf{2 0 1 7}$ & $\mathbf{2 0 1 8}$ & $\mathbf{2 0 1 9}$ \\
\hline Jan & - & 14 & 86 & 145 & 230 & 499 \\
\hline Feb & - & 32 & 70 & 168 & 291 & 527 \\
\hline Mar & - & 49 & 71 & 118 & 299 & 542 \\
\hline Apr & - & 52 & 90 & 110 & 319 & 451 \\
\hline May & - & 42 & 109 & 151 & 243 & 393 \\
\hline Jun & - & 47 & 94 & 153 & 237 & 330 \\
\hline Jul & - & 28 & 59 & 117 & 141 & 190 \\
\hline Aug & - & 46 & 50 & 129 & 172 & 248 \\
\hline Sep & - & 90 & 143 & 245 & 291 & 411 \\
\hline Oct & $-(5)$ & 91 & 155 & 203 & 304 & 489 \\
\hline Nov & $-(26)$ & 39 & 149 & 297 & 298 & 534 \\
\hline Dec & $-(4)$ & 25 & 114 & 232 & 237 & 416 \\
\hline
\end{tabular}

Stationarity is an important concept when working with time series data. A stationary series is in which the properties like mean, variance and covariance do not vary with time. Before applying time-series analysis and forecasting predictions, it is important to test the stationarity of real time data, because usually maximum real time data would be nonstationary. There are several ways to test stationarity those are - visual test (through graphs) and statistical test (Augmented Dickey Fuller test [ADF] and Kwiatkowski-PhillipsSchmidt-Shin test (KPSS), since statistical tests are more accurate, I chose ADF test.

Null Hypothesis: The series has a unit root, series is non-stationary, Alternate Hypothesis: The series has no unit root, series is stationary. 
ADF Test: The Dickey Fuller test is a popular statistical test to verify the stationarity of the data and works through determining the presence of unit root in the series which are the reason for non-stationary. Test statistics value has to be negative, the more negative than critical values, the more data is stationary.

- If we fail to reject null hypothesis, we can say that the series is non-stationary.

- If we reject Null, and considered alternate hypothesis valid, we can say that the series is stationary.

\section{Augmented Dickey-Fuller (ADF) Statistical test Results}

\begin{tabular}{|l|l|l|c|}
\hline Data point & ADF - Test Statistics & p-Value & Critical value ranges \\
\hline Actual Values & & & \multirow{2}{*}{$1 \%:-3.575$} \\
\hline Actual Values - 0 diff & 3.153606 & 1.000000 & $5 \%:-2.924$ \\
\hline Actual Values - 1 diff & -2.646546 & 0.083754 & $10 \%:-2.600$ \\
\hline Actual Values - 2 diff & -5.126300 & 0.000012 & \\
\hline
\end{tabular}

Results of ADF Test: The ADF gives the following results - test statistics, $p$ value and the critical value at $1 \%, 5 \%$, and $10 \%$ confidence intervals. For actual values I got positive

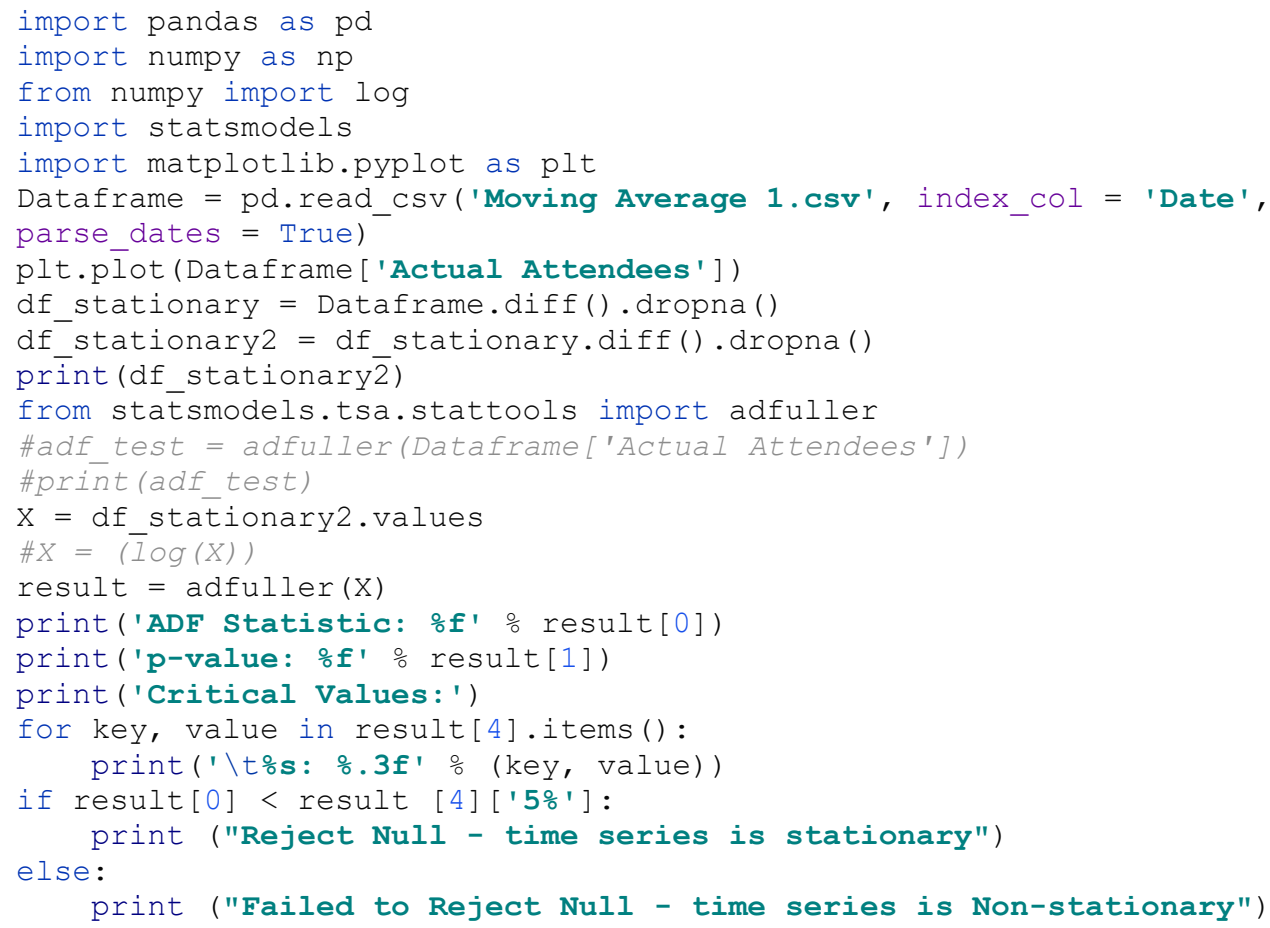


$\mathrm{ADF}$ test statistics value and $\mathrm{p}$-value greater than 0.05 , means my data is non-stationary. Since it was non-stationary, checked by differentiating the actual values. For one differentiation of 60 observations data, the statistics test yields value of -2.64 which is not far negative even than the critical value of -2.92 at $95 \%$ level, so the null hypothesis of a unit root cannot be rejected at this point, means data is still non-stationary at this differentiation level. For two differentiations of 60 observations data, the statistics test yields value of -5.12 which is more negative than the critical value of -3.57 and less $p$ value 0.000012 at $99 \%$ level the null hypothesis of a unit root can be rejected at this point, means data will become more stationary at this differentiation level.

\section{Simple Moving Average Time series Forecasting process}

For the conversion of non-stationary data to stationary as part of preprocessing of data, followed two differentiations, Differentiation 1: Differentiation through Moving Average (to make mean equal and stable), Differentiation 2: Seasonal differentiation (to make variance equal and stable).

Simple Moving Average Time Series Procedure
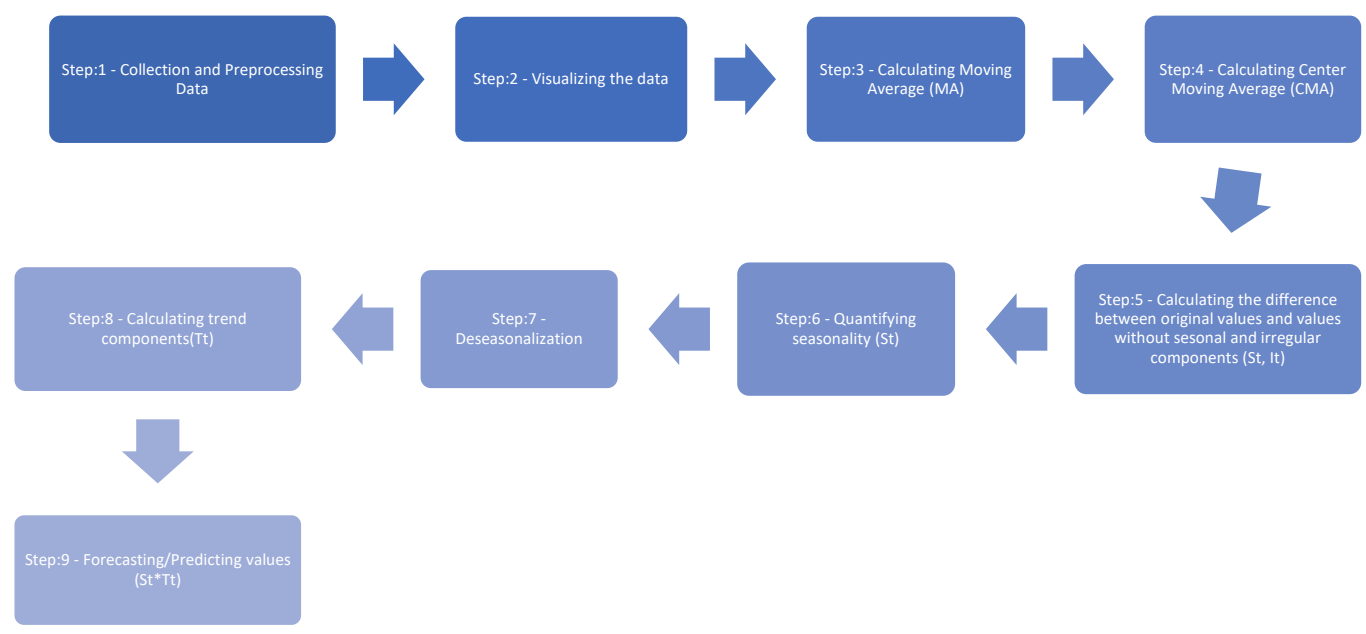
a) Step: 1 - Collection and Preprocessing Data: Considered Quantitative monthly data about who attended ECHO sessions in particular month and number of attendees including facilitators from January 2015 to December 2019.

\section{Monthly Actual Attendance (2015-2019)}

\begin{tabular}{|l|l|l|l|l|l|}
\hline Month & $\mathbf{2 0 1 5}$ & $\mathbf{2 0 1 6}$ & $\mathbf{2 0 1 7}$ & $\mathbf{2 0 1 8}$ & $\mathbf{2 0 1 9}$ \\
\hline Jan & 14 & 86 & 145 & 230 & 499 \\
\hline Feb & 32 & 70 & 168 & 291 & 527 \\
\hline Mar & 49 & 71 & 118 & 299 & 542 \\
\hline Apr & 52 & 90 & 110 & 319 & 451 \\
\hline May & 42 & 109 & 151 & 243 & 393 \\
\hline Jun & 47 & 94 & 153 & 237 & 330 \\
\hline Jul & 28 & 59 & 117 & 141 & 190 \\
\hline Aug & 46 & 50 & 129 & 172 & 248 \\
\hline Sep & 90 & 143 & 245 & 291 & 411 \\
\hline Oct & 91 & 155 & 203 & 304 & 489 \\
\hline Nov & 39 & 149 & 297 & 298 & 534 \\
\hline Dec & 25 & 114 & 232 & 237 & 416 \\
\hline
\end{tabular}

b) Step: 2 - Visualizing Data: To identify time series components such as trend, seasonality, and irregularity, visualized the data using line chart with markers and at the same point with visualizations observing the trends in actual data/numbers will be easy.

\section{Timeseries of number of attendees in all ECHO Sessions 2015-2019}

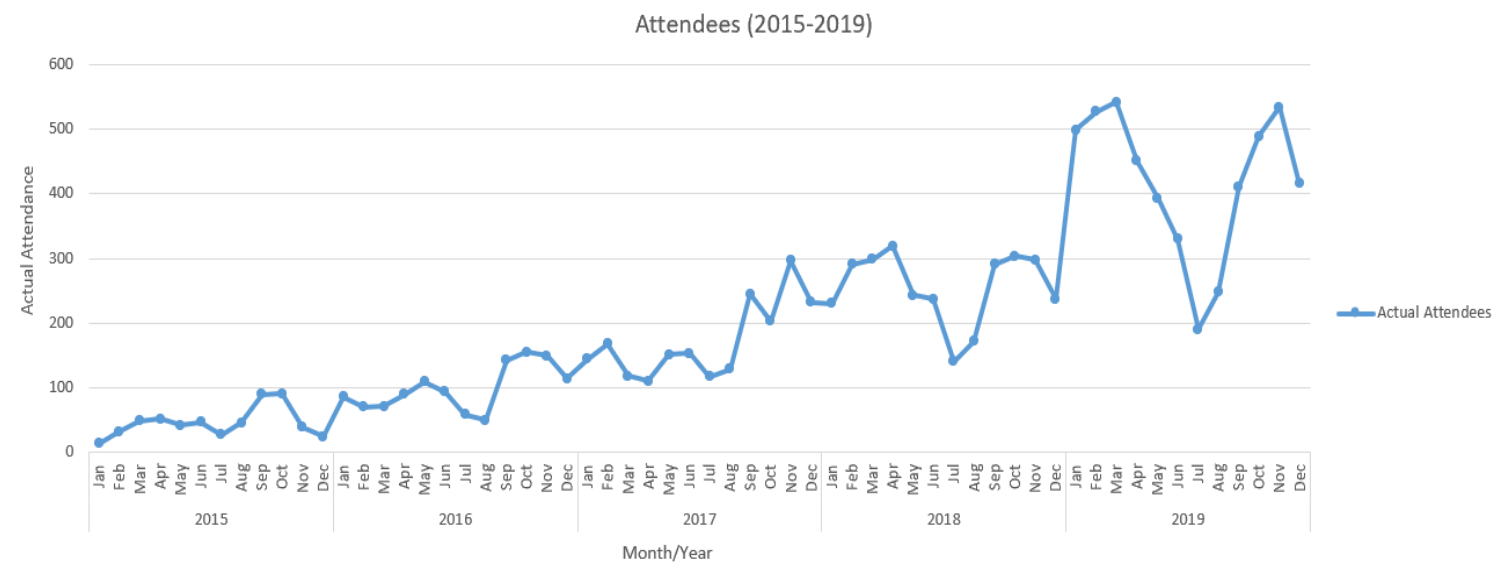


With this graph, found out that the data in early years are not stable in order of variations, sessions have less attendance, the reason could be that Telehealth or ECHO sessions are newly emerging health technology during that time. Also, we can observe that the number of participants is increasing with time period, and we may have more data in future which can help in accurate predictions.

c) Step: 3 - Calculating Simple Moving Average: To smooth out the data, ironing/flatten out the up and downs (irregularities/seasonality).

\section{Moving Average Calculation MA (12)}

\begin{tabular}{|c|c|c|c|c|c|c|c|}
\hline Year & Month & Actual Attendees & MA (12) & & & & \\
\hline \multirow[t]{12}{*}{2015} & Jan & 14 & & & Jul & 117 & 179.4167 \\
\hline & Feb & 32 & & & Aug & 129 & 189.6667 \\
\hline & Mar & 49 & & & Sep & 245 & 204.75 \\
\hline & Apr & 52 & & & Oct & 203 & 222.1667 \\
\hline & May & 42 & & & Nov & 297 & 229.8333 \\
\hline & Jun & 47 & 46.25 & & Dec & 232 & 236.8333 \\
\hline & Jul & 28 & 52.25 & 2018 & Jan & 230 & 238.8333 \\
\hline & Aug & 46 & 55.41667 & & Feb & 291 & 242.4167 \\
\hline & Sep & 90 & 57.25 & & Mar & 299 & 246.25 \\
\hline & Oct & 91 & 60.41667 & & Apr & 319 & 254.6667 \\
\hline & Nov & 39 & 66 & & May & 243 & 254.75 \\
\hline & Dec & 25 & 69.91667 & & Jun & 237 & 255.1667 \\
\hline \multirow[t]{12}{*}{2016} & Jan & 86 & 72.5 & & Jul & 141 & 277.5833 \\
\hline & Feb & 70 & 72.83333 & & Aug & 172 & 297.25 \\
\hline & Mar & 71 & 77.25 & & Sep & 291 & 317.5 \\
\hline & Apr & 90 & 82.58333 & & Oct & 304 & 328.5 \\
\hline & May & 109 & 91.75 & & Nov & 298 & 341 \\
\hline & Jun & 94 & 99.16667 & & Dec & 237 & 348.75 \\
\hline & Jul & 59 & 104.0833 & 2019 & Jan & 499 & 352.8333 \\
\hline & Aug & 50 & 112.25 & & Feb & 527 & 359.1667 \\
\hline & Sep & 143 & 116.1667 & & Mar & 542 & 369.1667 \\
\hline & Oct & 155 & 117.8333 & & Apr & 451 & 384.5833 \\
\hline & Nov & 149 & 121.3333 & & May & 393 & 404.25 \\
\hline & Dec & 114 & 126.25 & & Jun & 330 & 419.1667 \\
\hline \multirow[t]{6}{*}{2017} & Jan & 145 & 131.0833 & & Jul & 190 & \\
\hline & Feb & 168 & 137.6667 & & Aug & 248 & \\
\hline & Mar & 118 & 146.1667 & & Sep & 411 & \\
\hline & Apr & 110 & 150.1667 & & Oct & 489 & \\
\hline & May & 151 & 162.5 & & Nov & 534 & \\
\hline & Jun & 153 & 172.3333 & & Dec & 416 & \\
\hline
\end{tabular}


d) Step: 4 - Calculating Center Moving Average: In order to maintain proper association of moving average values to original data and also to get rid of seasonality and irregularity components.

\section{Centered Simple Moving Average Calculation CMA (12)}

\begin{tabular}{|c|c|c|c|c|c|c|c|c|c|}
\hline Year & Month & $\begin{array}{l}\text { Actual } \\
\text { Attendees }\end{array}$ & МА (12) & CMA (12) & & & & & \\
\hline \multirow[t]{12}{*}{2015} & Jan & 14 & & & & Jul & 117 & 179.4167 & 184.5417 \\
\hline & Feb & 32 & & & & Aug & 129 & 189.6667 & 197.2083 \\
\hline & Mar & 49 & & & & Sep & 245 & 204.75 & 213.4583 \\
\hline & Apr & 52 & & & & Oct & 203 & 222.1667 & 226 \\
\hline & May & 42 & & & & Nov & 297 & 229.8333 & 233.3333 \\
\hline & Jun & 47 & 46.25 & 49.25 & & Dec & 232 & 236.8333 & 237.8333 \\
\hline & Jul & 28 & 52.25 & 53.83333 & 2018 & Jan & 230 & 238.8333 & 240.625 \\
\hline & Aug & 46 & 55.41667 & 56.33333 & & Feb & 291 & 242.4167 & 244.3333 \\
\hline & Sep & 90 & 57.25 & 58.83333 & & Mar & 299 & 246.25 & 250.4583 \\
\hline & Oct & 91 & 60.41667 & 63.20833 & & Apr & 319 & 254.6667 & 254.7083 \\
\hline & Nov & 39 & 66 & 67.95833 & & May & 243 & 254.75 & 254.9583 \\
\hline & Dec & 25 & 69.91667 & 71.20833 & & Jun & 237 & 255.1667 & 266.375 \\
\hline \multirow[t]{12}{*}{2016} & Jan & 86 & 72.5 & 72.66667 & & Jul & 141 & 277.5833 & 287.4167 \\
\hline & Feb & 70 & 72.83333 & 75.04167 & & Aug & 172 & 297.25 & 307.375 \\
\hline & Mar & 71 & 77.25 & 79.91667 & & Sep & 291 & 317.5 & 323 \\
\hline & Apr & 90 & 82.58333 & 87.16667 & & Oct & 304 & 328.5 & 334.75 \\
\hline & May & 109 & 91.75 & 95.45833 & & Nov & 298 & 341 & 344.875 \\
\hline & Jun & 94 & 99.16667 & 101.625 & & Dec & 237 & 348.75 & 350.7917 \\
\hline & Jul & 59 & 104.0833 & 108.1667 & 2019 & Jan & 499 & 352.8333 & 356 \\
\hline & Aug & 50 & 112.25 & 114.2083 & & Feb & 527 & 359.1667 & 364.1667 \\
\hline & Sep & 143 & 116.1667 & 117 & & Mar & 542 & 369.1667 & 376.875 \\
\hline & Oct & 155 & 117.8333 & 119.5833 & & Apr & 451 & 384.5833 & 394.4167 \\
\hline & Nov & 149 & 121.3333 & 123.7917 & & May & 393 & 404.25 & 411.7083 \\
\hline & Dec & 114 & 126.25 & 128.6667 & & Jun & 330 & 419.1667 & \\
\hline \multirow[t]{6}{*}{2017} & Jan & 145 & 131.0833 & 134.375 & & Jul & 190 & & \\
\hline & Feb & 168 & 137.6667 & 141.9167 & & Aug & 248 & & \\
\hline & Mar & 118 & 146.1667 & 148.1667 & & Sep & 411 & & \\
\hline & Apr & 110 & 150.1667 & 156.3333 & & Oct & 489 & & \\
\hline & May & 151 & 162.5 & 167.4167 & & Nov & 534 & & \\
\hline & Jun & 153 & 172.3333 & 175.875 & & Dec & 416 & & \\
\hline
\end{tabular}




\section{Timeseries of number of attendees in all ECHO Sessions with CMA 2015-2019}

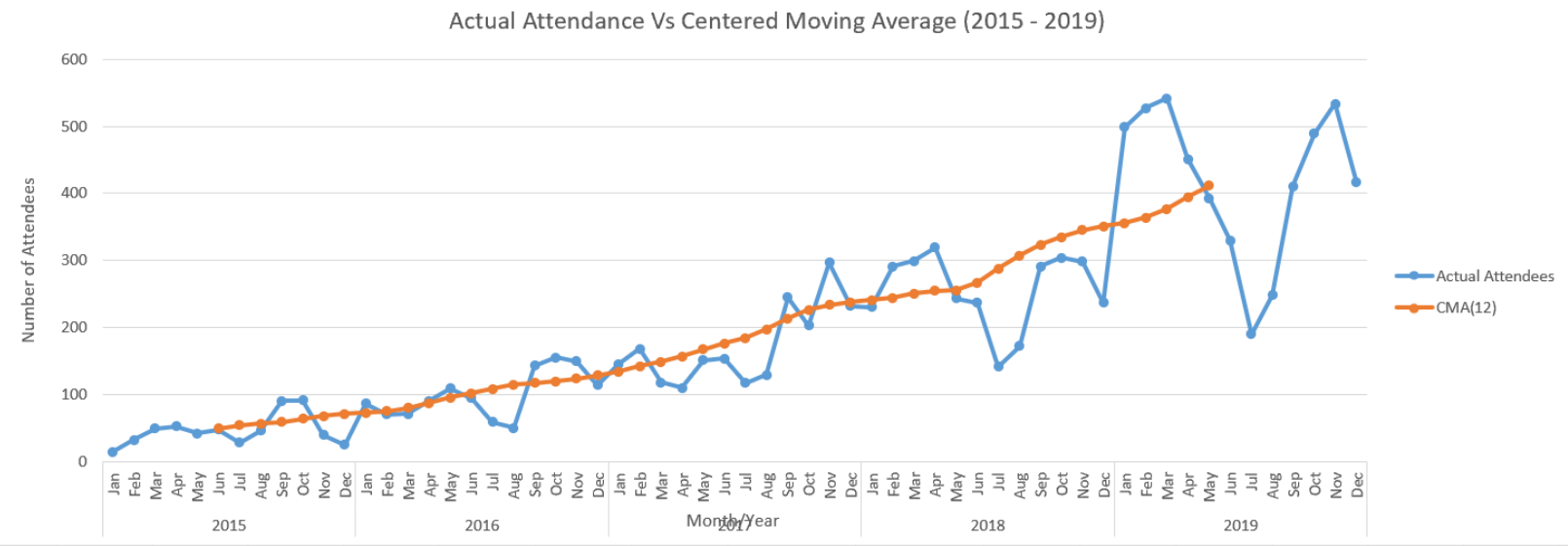

e) Step: 5 - Calculating difference between original values and values without seasonal and irregular components (to identify actual variation in values. (By dividing original value with CMA))

\section{St, It (Seasonality and Irregularity) Calculation}

\begin{tabular}{|c|c|c|c|c|c|c|c|c|c|c|c|}
\hline Year & Month & $\mathbf{Y t}$ & MA (12) & СМА(12) & St, It & & & & & & \\
\hline \multirow[t]{12}{*}{2015} & Jan & 14 & & & & & Jul & 117 & 179.4167 & 184.5417 & 0.634003 \\
\hline & Feb & 32 & & & & & Aug & 129 & 189.6667 & 197.2083 & 0.654131 \\
\hline & Mar & 49 & & & & & Sep & 245 & 204.75 & 213.4583 & 1.147765 \\
\hline & Apr & 52 & & & & & Oct & 203 & 222.1667 & 226 & 0.89823 \\
\hline & May & 42 & & & & & Nov & 297 & 229.8333 & 233.3333 & 1.272857 \\
\hline & Jun & 47 & 46.25 & 49.25 & 0.954315 & & Dec & 232 & 236.8333 & 237.8333 & 0.975473 \\
\hline & Jul & 28 & 52.25 & 53.83333 & 0.520124 & 2018 & Jan & 230 & 238.8333 & 240.625 & 0.955844 \\
\hline & Aug & 46 & 55.41667 & 56.33333 & 0.816568 & & Feb & 291 & 242.4167 & 244.3333 & 1.190996 \\
\hline & Sep & 90 & 57.25 & 58.83333 & 1.529745 & & Mar & 299 & 246.25 & 250.4583 & 1.193811 \\
\hline & Oct & 91 & 60.41667 & 63.20833 & 1.439684 & & Apr & 319 & 254.6667 & 254.7083 & 1.252413 \\
\hline & Nov & 39 & 66 & 67.95833 & 0.573881 & & May & 243 & 254.75 & 254.9583 & 0.953097 \\
\hline & Dec & 25 & 69.91667 & 71.20833 & 0.351083 & & Jun & 237 & 255.1667 & 266.375 & 0.889723 \\
\hline \multirow[t]{12}{*}{2016} & Jan & 86 & 72.5 & 72.66667 & 1.183486 & & Jul & 141 & 277.5833 & 287.4167 & 0.490577 \\
\hline & Feb & 70 & 72.83333 & 75.04167 & 0.932815 & & Aug & 172 & 297.25 & 307.375 & 0.559577 \\
\hline & Mar & 71 & 77.25 & 79.91667 & 0.888425 & & Sep & 291 & 317.5 & 323 & 0.900929 \\
\hline & Apr & 90 & 82.58333 & 87.16667 & 1.032505 & & Oct & 304 & 328.5 & 334.75 & 0.90814 \\
\hline & May & 109 & 91.75 & 95.45833 & 1.141859 & & Nov & 298 & 341 & 344.875 & 0.864081 \\
\hline & Jun & 94 & 99.16667 & 101.625 & 0.924969 & & Dec & 237 & 348.75 & 350.7917 & 0.675615 \\
\hline & Jul & 59 & 104.0833 & 108.1667 & 0.545455 & 2019 & Jan & 499 & 352.8333 & 356 & 1.401685 \\
\hline & Aug & 50 & 112.25 & 114.2083 & 0.437796 & & Feb & 527 & 359.1667 & 364.1667 & 1.44714 \\
\hline & Sep & 143 & 116.1667 & 117 & 1.222222 & & Mar & 542 & 369.1667 & 376.875 & 1.438143 \\
\hline & Oct & 155 & 117.8333 & 119.5833 & 1.296167 & & Apr & 451 & 384.5833 & 394.4167 & 1.143461 \\
\hline & Nov & 149 & 121.3333 & 123.7917 & 1.203635 & & May & 393 & 404.25 & 411.7083 & 0.954559 \\
\hline & Dec & 114 & 126.25 & 128.6667 & 0.88601 & & Jun & 330 & 419.1667 & & \\
\hline \multirow[t]{2}{*}{2017} & Jan & 145 & 131.0833 & 134.375 & 1.07907 & & Jul & 190 & & & \\
\hline & Feb & 168 & 137.6667 & 141.9167 & 1.183793 & & Aug & 248 & & & \\
\hline
\end{tabular}




\begin{tabular}{|l|l|l|l|l|l|l|l|l|l|l|l|}
\hline & Mar & 118 & 146.1667 & 148.1667 & 0.7964 & & Sep & 411 & & & \\
\hline & Apr & 110 & 150.1667 & 156.3333 & 0.703625 & & Oct & 489 & & & \\
\hline & May & 151 & 162.5 & 167.4167 & 0.901941 & & Nov & 534 & & & \\
\hline & Jun & 153 & 172.3333 & 175.875 & 0.869936 & & Dec & 416 & & & \\
\hline
\end{tabular}

f) Step: 6-Quantifying Seasonality: To eliminate/get rid of irregularity (It), per each month (average of same month in every year)

\section{Seasonal Component (St) Calculation}

\begin{tabular}{|l|l|}
\hline Month & St \\
\hline Jan & 1.16 \\
\hline Feb & 1.19 \\
\hline Mar & 1.08 \\
\hline Apr & 1.03 \\
\hline May & 0.99 \\
\hline Jun & 0.91 \\
\hline Jul & 0.55 \\
\hline Aug & 0.62 \\
\hline Sep & 1.20 \\
\hline Oct & 1.18 \\
\hline Nov & 0.98 \\
\hline Dec & 0.72 \\
\hline
\end{tabular}

g) Step: 7 - De-seasonalization: dividing original value with seasonality (St)

\section{De-seasonalized Data}

\begin{tabular}{|l|l|l|l|l|l|l|l|}
\hline Year & Month & Actual Attendees & MA (12) & CMA (12) & St, It & St & De-seasonalize \\
\hline $\mathbf{2 0 1 5}$ & Jan & 14 & & & & 1.16 & 12.12098766 \\
\hline & Feb & 32 & & & & 1.19 & 26.92048249 \\
\hline & Mar & 49 & & & & 1.08 & 45.40421481 \\
\hline & Apr & 52 & & & & 1.03 & 50.33877985 \\
\hline & May & 42 & & & & 0.99 & 42.51596438 \\
\hline & Jun & 47 & 46.25 & 49.25 & 0.954315 & 0.91 & 51.66335191 \\
\hline & Jul & 28 & 52.25 & 53.83333 & 0.520124 & 0.55 & 51.13785087 \\
\hline & Aug & 46 & 55.41667 & 56.33333 & 0.816568 & 0.62 & 74.55211676 \\
\hline & Sep & 90 & 57.25 & 58.83333 & 1.529745 & 1.20 & 74.98967269 \\
\hline & Oct & 91 & 60.41667 & 63.20833 & 1.439684 & 1.18 & 77.27254114 \\
\hline & Nov & 39 & 66 & 67.95833 & 0.573881 & 0.98 & 39.85229589 \\
\hline & Dec & 25 & 69.91667 & 71.20833 & 0.351083 & 0.72 & 34.62387397 \\
\hline $\mathbf{2 0 1 6}$ & Jan & 86 & 72.5 & 72.66667 & 1.183486 & 1.16 & 74.45749562 \\
\hline
\end{tabular}




\begin{tabular}{|c|c|c|c|c|c|c|c|}
\hline & Feb & 70 & 72.83333 & 75.04167 & 0.932815 & 1.19 & 58.88855544 \\
\hline & Mar & 71 & 77.25 & 79.91667 & 0.888425 & 1.08 & 65.78978064 \\
\hline & Apr & 90 & 82.58333 & 87.16667 & 1.032505 & 1.03 & 87.12481128 \\
\hline & May & 109 & 91.75 & 95.45833 & 1.141859 & 0.99 & 110.3390504 \\
\hline & Jun & 94 & 99.16667 & 101.625 & 0.924969 & 0.91 & 103.3267038 \\
\hline & Jul & 59 & 104.0833 & 108.1667 & 0.545455 & 0.55 & 107.7547572 \\
\hline & Aug & 50 & 112.25 & 114.2083 & 0.437796 & 0.62 & 81.03490952 \\
\hline & Sep & 143 & 116.1667 & 117 & 1.222222 & 1.20 & 119.1502577 \\
\hline & Oct & 155 & 117.8333 & 119.5833 & 1.296167 & 1.18 & 131.6180646 \\
\hline & Nov & 149 & 121.3333 & 123.7917 & 1.203635 & 0.98 & 152.2562074 \\
\hline & Dec & 114 & 126.25 & 128.6667 & 0.88601 & 0.72 & 157.8848653 \\
\hline \multirow[t]{12}{*}{2017} & Jan & 145 & 131.0833 & 134.375 & 1.07907 & 1.16 & 125.5388008 \\
\hline & Feb & 168 & 137.6667 & 141.9167 & 1.183793 & 1.19 & 141.3325331 \\
\hline & Mar & 118 & 146.1667 & 148.1667 & 0.7964 & 1.08 & 109.3407622 \\
\hline & Apr & 110 & 150.1667 & 156.3333 & 0.703625 & 1.03 & 106.4858805 \\
\hline & May & 151 & 162.5 & 167.4167 & 0.901941 & 0.99 & 152.8550148 \\
\hline & Jun & 153 & 172.3333 & 175.875 & 0.869936 & 0.91 & 168.1806988 \\
\hline & Jul & 117 & 179.4167 & 184.5417 & 0.634003 & 0.55 & 213.6831626 \\
\hline & Aug & 129 & 189.6667 & 197.2083 & 0.654131 & 0.62 & 209.0700666 \\
\hline & Sep & 245 & 204.75 & 213.4583 & 1.147765 & 1.20 & 204.1385534 \\
\hline & Oct & 203 & 222.1667 & 226 & 0.89823 & 1.18 & 172.3772072 \\
\hline & Nov & 297 & 229.8333 & 233.3333 & 1.272857 & 0.98 & 303.490561 \\
\hline & Dec & 232 & 236.8333 & 237.8333 & 0.975473 & 0.72 & 321.3095504 \\
\hline \multirow[t]{12}{*}{2018} & Jan & 230 & 238.8333 & 240.625 & 0.955844 & 1.16 & 199.1305116 \\
\hline & Feb & 291 & 242.4167 & 244.3333 & 1.190996 & 1.19 & 244.8081376 \\
\hline & Mar & 299 & 246.25 & 250.4583 & 1.193811 & 1.08 & 277.058372 \\
\hline & Apr & 319 & 254.6667 & 254.7083 & 1.252413 & 1.03 & 308.8090533 \\
\hline & May & 243 & 254.75 & 254.9583 & 0.953097 & 0.99 & 245.9852225 \\
\hline & Jun & 237 & 255.1667 & 266.375 & 0.889723 & 0.91 & 260.5152001 \\
\hline & Jul & 141 & 277.5833 & 287.4167 & 0.490577 & 0.55 & 257.5156062 \\
\hline & Aug & 172 & 297.25 & 307.375 & 0.559577 & 0.62 & 278.7600888 \\
\hline & Sep & 291 & 317.5 & 323 & 0.900929 & 1.20 & 242.4666084 \\
\hline & Oct & 304 & 328.5 & 334.75 & 0.90814 & 1.18 & 258.1412363 \\
\hline & Nov & 298 & 341 & 344.875 & 0.864081 & 0.98 & 304.5124147 \\
\hline & Dec & 237 & 348.75 & 350.7917 & 0.675615 & 0.72 & 328.2343252 \\
\hline \multirow[t]{8}{*}{2019} & Jan & 499 & 352.8333 & 356 & 1.401685 & 1.16 & 432.0266316 \\
\hline & Feb & 527 & 359.1667 & 364.1667 & 1.44714 & 1.19 & 443.346696 \\
\hline & Mar & 542 & 369.1667 & 376.875 & 1.438143 & 1.08 & 502.2262128 \\
\hline & Apr & 451 & 384.5833 & 394.4167 & 1.143461 & 1.03 & 436.5921099 \\
\hline & May & 393 & 404.25 & 411.7083 & 0.954559 & 0.99 & 397.8279524 \\
\hline & Jun & 330 & 419.1667 & & & 0.91 & 362.7426837 \\
\hline & Jul & 190 & & & & 0.55 & 347.0068452 \\
\hline & Aug & 248 & & & & 0.62 & 401.9331512 \\
\hline
\end{tabular}




\begin{tabular}{|l|l|l|l|l|l|l|l|}
\hline & Sep & 411 & & & & 1.20 & 342.4528386 \\
\hline & Oct & 489 & & & & 1.18 & 415.233765 \\
\hline & Nov & 534 & & & & 0.98 & 545.6698975 \\
\hline & Dec & 416 & & & & 0.72 & 576.1412628 \\
\hline
\end{tabular}

h) Step: 8 - Calculating Trend components: with series of periods $(\mathrm{t})$, for this finding out intercept and values of through Simple Linear Regression on original data

\section{Simple Moving Average - Regression Analysis}

\section{SUMMARY OUTPUT}

\begin{tabular}{lr}
\hline \multicolumn{2}{c}{ Regression Statistics } \\
\hline Multiple R & 0.937134 \\
R Square & $\mathbf{0 . 8 7 8 2 2 1}$ \\
Adjusted R & \\
Square & 0.876121 \\
Standard & \\
Error & 50.96919 \\
Observations & 60 \\
\hline
\end{tabular}

ANOVA

\begin{tabular}{|c|c|c|c|c|c|c|c|c|}
\hline & $d f$ & $S S$ & $M S$ & $F$ & $\begin{array}{c}\text { Significance } \\
F \\
\end{array}$ & & & \\
\hline Regression & 1 & 1086609 & 1086609 & 418.2711133 & $3.36661 \mathrm{E}-28$ & & & \\
\hline Residual & 58 & 150675.8 & 2597.858 & & & & & \\
\hline \multirow[t]{2}{*}{ Total } & 59 & 1237285 & & & & & & \\
\hline & Coefficients & $\begin{array}{l}\text { Standard } \\
\text { Error }\end{array}$ & $t$ Stat & P-value & Lower 95\% & $\begin{array}{l}\text { Upper } \\
95 \%\end{array}$ & $\begin{array}{l}\text { Lower } \\
95.0 \%\end{array}$ & $\begin{array}{l}\text { Upper } \\
95.0 \%\end{array}$ \\
\hline Intercept & -29.2074 & 13.32643 & -2.191689 & 0.032430633 & -55.8831387 & -2.531647 & -55.88314 & -2.531647 \\
\hline $\mathrm{t}$ & 7.770711 & 0.379955 & 20.45168 & $3.36661 \mathrm{E}-28$ & 7.01014886 & 8.531273 & 7.010149 & 8.531273 \\
\hline
\end{tabular}

\section{Trend Component Calculation (Tt)}

\begin{tabular}{|l|l|l|l|l|l|l|l|l|l|}
\hline $\mathbf{t}$ & Year & Month & $\begin{array}{l}\text { Actual } \\
\text { Attendees }\end{array}$ & MA (12) & CMA (12) & St, It & St & Deseasonalize & Tt \\
\hline 1 & $\mathbf{2 0 1 5}$ & Jan & 14 & & & & 1.16 & 12.12098766 & -21.4367 \\
\hline 2 & & Feb & 32 & & & & 1.19 & 26.92048249 & -13.666 \\
\hline 3 & & Mar & 49 & & & & 1.08 & 45.40421481 & -5.89526 \\
\hline 4 & & Apr & 52 & & & & 1.03 & 50.33877985 & 1.87545 \\
\hline 5 & & May & 42 & & & & 0.99 & 42.51596438 & 9.646161 \\
\hline 6 & & Jun & 47 & 46.25 & 49.25 & 0.954315 & 0.91 & 51.66335191 & 17.41687 \\
\hline 7 & & Jul & 28 & 52.25 & 53.83333 & 0.520124 & 0.55 & 51.13785087 & 25.18758 \\
\hline 8 & & Aug & 46 & 55.41667 & 56.33333 & 0.816568 & 0.62 & 74.55211676 & 32.95829 \\
\hline 9 & & Sep & 90 & 57.25 & 58.83333 & 1.529745 & 1.20 & 74.98967269 & 40.729 \\
\hline
\end{tabular}




\begin{tabular}{|c|c|c|c|c|c|c|c|c|c|}
\hline 10 & & Oct & 91 & 60.41667 & 63.20833 & 1.439684 & 1.18 & 77.27254114 & 48.49972 \\
\hline 11 & & Nov & 39 & 66 & 67.95833 & 0.573881 & 0.98 & 39.85229589 & 56.27043 \\
\hline 12 & & Dec & 25 & 69.91667 & 71.20833 & 0.351083 & 0.72 & 34.62387397 & 64.04114 \\
\hline 13 & 2016 & Jan & 86 & 72.5 & 72.66667 & 1.183486 & 1.16 & 74.45749562 & 71.81185 \\
\hline 14 & & Feb & 70 & 72.83333 & 75.04167 & 0.932815 & 1.19 & 58.88855544 & 79.58256 \\
\hline 15 & & Mar & 71 & 77.25 & 79.91667 & 0.888425 & 1.08 & 65.78978064 & 87.35327 \\
\hline 16 & & Apr & 90 & 82.58333 & 87.16667 & 1.032505 & 1.03 & 87.12481128 & 95.12398 \\
\hline 17 & & May & 109 & 91.75 & 95.45833 & 1.141859 & 0.99 & 110.3390504 & 102.8947 \\
\hline 18 & & Jun & 94 & 99.16667 & 101.625 & 0.924969 & 0.91 & 103.3267038 & 110.6654 \\
\hline 19 & & Jul & 59 & 104.0833 & 108.1667 & 0.545455 & 0.55 & 107.7547572 & 118.4361 \\
\hline 20 & & Aug & 50 & 112.25 & 114.2083 & 0.437796 & 0.62 & 81.03490952 & 126.2068 \\
\hline 21 & & Sep & 143 & 116.1667 & 117 & 1.222222 & 1.20 & 119.1502577 & 133.9775 \\
\hline 22 & & Oct & 155 & 117.8333 & 119.5833 & 1.296167 & 1.18 & 131.6180646 & 141.7482 \\
\hline 23 & & Nov & 149 & 121.3333 & 123.7917 & 1.203635 & 0.98 & 152.2562074 & 149.519 \\
\hline 24 & & Dec & 114 & 126.25 & 128.6667 & 0.88601 & 0.72 & 157.8848653 & 157.2897 \\
\hline 25 & 2017 & Jan & 145 & 131.0833 & 134.375 & 1.07907 & 1.16 & 125.5388008 & 165.0604 \\
\hline 26 & & Feb & 168 & 137.6667 & 141.9167 & 1.183793 & 1.19 & 141.3325331 & 172.8311 \\
\hline 27 & & Mar & 118 & 146.1667 & 148.1667 & 0.7964 & 1.08 & 109.3407622 & 180.6018 \\
\hline 28 & & Apr & 110 & 150.1667 & 156.3333 & 0.703625 & 1.03 & 106.4858805 & 188.3725 \\
\hline 29 & & May & 151 & 162.5 & 167.4167 & 0.901941 & 0.99 & 152.8550148 & 196.1432 \\
\hline 30 & & Jun & 153 & 172.3333 & 175.875 & 0.869936 & 0.91 & 168.1806988 & 203.9139 \\
\hline 31 & & Jul & 117 & 179.4167 & 184.5417 & 0.634003 & 0.55 & 213.6831626 & 211.6846 \\
\hline 32 & & Aug & 129 & 189.6667 & 197.2083 & 0.654131 & 0.62 & 209.0700666 & 219.4554 \\
\hline 33 & & Sep & 245 & 204.75 & 213.4583 & 1.147765 & 1.20 & 204.1385534 & 227.2261 \\
\hline 34 & & Oct & 203 & 222.1667 & 226 & 0.89823 & 1.18 & 172.3772072 & 234.9968 \\
\hline 35 & & Nov & 297 & 229.8333 & 233.3333 & 1.272857 & 0.98 & 303.490561 & 242.7675 \\
\hline 36 & & Dec & 232 & 236.8333 & 237.8333 & 0.975473 & 0.72 & 321.3095504 & 250.5382 \\
\hline 37 & 2018 & Jan & 230 & 238.8333 & 240.625 & 0.955844 & 1.16 & 199.1305116 & 258.3089 \\
\hline 38 & & Feb & 291 & 242.4167 & 244.3333 & 1.190996 & 1.19 & 244.8081376 & 266.0796 \\
\hline 39 & & Mar & 299 & 246.25 & 250.4583 & 1.193811 & 1.08 & 277.058372 & 273.8503 \\
\hline 40 & & Apr & 319 & 254.6667 & 254.7083 & 1.252413 & 1.03 & 308.8090533 & 281.621 \\
\hline 41 & & May & 243 & 254.75 & 254.9583 & 0.953097 & 0.99 & 245.9852225 & 289.3918 \\
\hline 42 & & Jun & 237 & 255.1667 & 266.375 & 0.889723 & 0.91 & 260.5152001 & 297.1625 \\
\hline 43 & & Jul & 141 & 277.5833 & 287.4167 & 0.490577 & 0.55 & 257.5156062 & 304.9332 \\
\hline 44 & & Aug & 172 & 297.25 & 307.375 & 0.559577 & 0.62 & 278.7600888 & 312.7039 \\
\hline 45 & & Sep & 291 & 317.5 & 323 & 0.900929 & 1.20 & 242.4666084 & 320.4746 \\
\hline 46 & & Oct & 304 & 328.5 & 334.75 & 0.90814 & 1.18 & 258.1412363 & 328.2453 \\
\hline 47 & & Nov & 298 & 341 & 344.875 & 0.864081 & 0.98 & 304.5124147 & 336.016 \\
\hline 48 & & Dec & 237 & 348.75 & 350.7917 & 0.675615 & 0.72 & 328.2343252 & 343.7867 \\
\hline 49 & 2019 & Jan & 499 & 352.8333 & 356 & 1.401685 & 1.16 & 432.0266316 & 351.5574 \\
\hline 50 & & Feb & 527 & 359.1667 & 364.1667 & 1.44714 & 1.19 & 443.346696 & 359.3281 \\
\hline 51 & & Mar & 542 & 369.1667 & 376.875 & 1.438143 & 1.08 & 502.2262128 & 367.0989 \\
\hline 52 & & Apr & 451 & 384.5833 & 394.4167 & 1.143461 & 1.03 & 436.5921099 & 374.8696 \\
\hline
\end{tabular}




\begin{tabular}{|l|l|l|l|l|l|l|l|l|l|}
\hline 53 & & May & 393 & 404.25 & 411.7083 & 0.954559 & 0.99 & 397.8279524 & 382.6403 \\
\hline 54 & & Jun & 330 & 419.1667 & & & 0.91 & 362.7426837 & 390.411 \\
\hline 55 & & Jul & 190 & & & & 0.55 & 347.0068452 & 398.1817 \\
\hline 56 & & Aug & 248 & & & & 0.62 & 401.9331512 & 405.9524 \\
\hline 57 & & Sep & 411 & & & & 1.20 & 342.4528386 & 413.7231 \\
\hline 58 & & Oct & 489 & & & & 1.18 & 415.233765 & 421.4938 \\
\hline 59 & & Nov & 534 & & & & 0.98 & 545.6698975 & 429.2645 \\
\hline 60 & & Dec & 416 & & & & 0.72 & 576.1412628 & 437.0353 \\
\hline
\end{tabular}

i) Step: 9 - MA - Prediction values:

SMA - Prediction values for past attendance (2015-2019)

\begin{tabular}{|l|l|l|l|l|l|l|}
\hline Month & $\mathbf{2 0 1 4}$ & $\mathbf{2 0 1 5}$ & $\mathbf{2 0 1 6}$ & $\mathbf{2 0 1 7}$ & $\mathbf{2 0 1 8}$ & $\mathbf{2 0 1 9}$ \\
\hline Jan & - & -25 & 83 & 191 & 298 & 406 \\
\hline Feb & - & -16 & 95 & 205 & 316 & 427 \\
\hline Mar & - & -6 & 94 & 195 & 296 & 396 \\
\hline Apr & - & 2 & 98 & 195 & 291 & 387 \\
\hline May & - & 10 & 102 & 194 & 286 & 378 \\
\hline Jun & - & 16 & 101 & 186 & 270 & 355 \\
\hline Jul & - & 14 & 65 & 116 & 167 & 218 \\
\hline Aug & - & 20 & 78 & 135 & 193 & 250 \\
\hline Sep & - & 49 & 161 & 273 & 385 & 497 \\
\hline Oct & NaN & 57 & 167 & 277 & 387 & 496 \\
\hline Nov & NaN & 55 & 146 & 238 & 329 & 420 \\
\hline Dec & NaN & 46 & 114 & 181 & 248 & 316 \\
\hline
\end{tabular}

SMA - Actual attendance Vs Predicted Values (2015 - 2019)

Actual attendance Vs Predicted Values

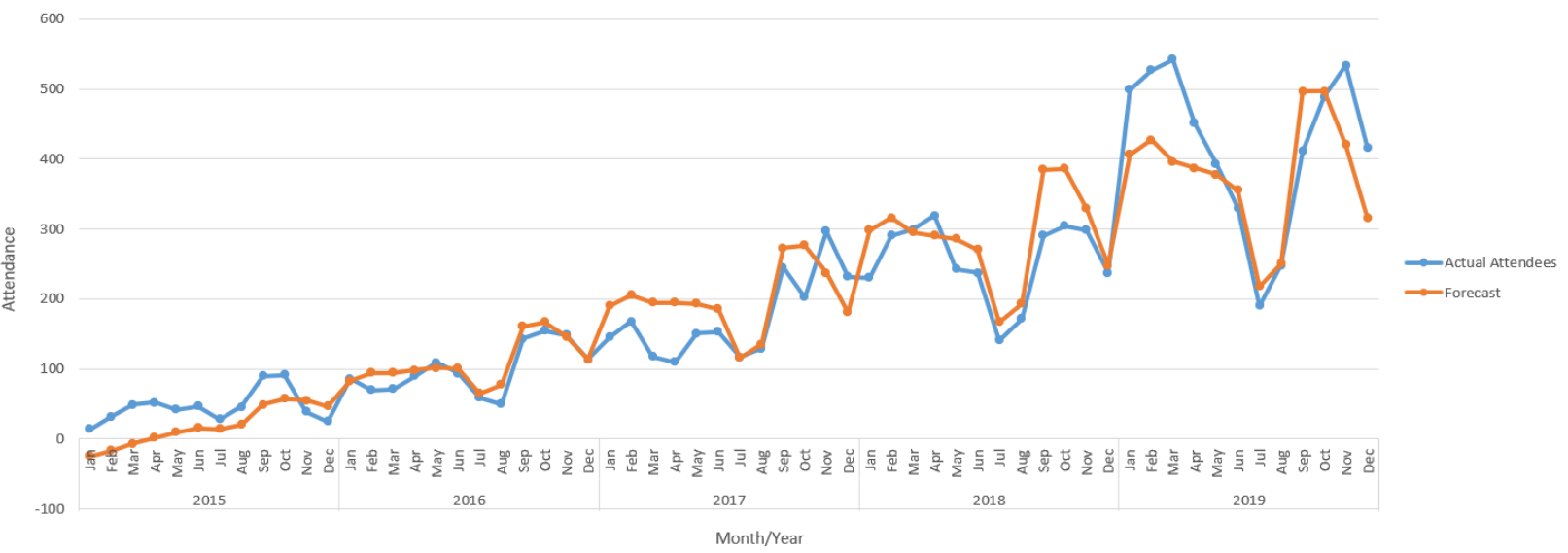




\section{ARIMA Time series Forecasting process}

Auto Regressive Integrated Moving Average models consist of specifying conditional mean of process, which are stochastic models specified as sum of simple or multiple linear relationships with lagged level or differentiation of variable model errors and constant mean or drift.

Differenced first-order autoregressive model consist of difference forecast equal to determine simple linear relationship with previous period data difference plus a constant drift. Considered ARIMA $(1,1,0)$ with constant.

As a Main formula:

$\mathrm{Ytf}=\mathrm{C}+\mathrm{Yt}-1+\mathrm{AR}(1) *((\mathrm{Yt}-1)-(\mathrm{Yt}-2))$

Current period forecast is equal to a constant drift plus previous periods data plus an autoregressive coefficient multiplied by the difference between (previous period - second previous period) data.

- Differentiation 1: DYt - Differentiated data (Current value - Previous value)

- Differentiation 2: $\mathrm{Ytf}-$ (previous period - second previous period)

ARIMA - Differentiation of training range data

\begin{tabular}{|l|l|l|l|l|l|l|l|}
\hline Year & Month & Yt & DYt & \multicolumn{5}{|l}{} \\
\hline $\mathbf{2 0 1 5}$ & Jan & 14 & 0 & & Jul & 117 & -36 \\
\hline & Feb & 32 & 18 & & Aug & 129 & 12 \\
\hline & Mar & 49 & 17 & & Sep & 245 & 116 \\
\hline & Apr & 52 & 3 & & Oct & 203 & -42 \\
\hline & May & 42 & -10 & & Nov & 297 & 94 \\
\hline & Jun & 47 & 5 & & Dec & 232 & -65 \\
\hline & Jul & 28 & -19 & $\mathbf{2 0 1 8}$ & Jan & 230 & -2 \\
\hline & Aug & 46 & 18 & & Feb & 291 & 61 \\
\hline & Sep & 90 & 44 & & Mar & 299 & 8 \\
\hline & Oct & 91 & 1 & & Apr & 319 & 20 \\
\hline & Nov & 39 & -52 & & May & 243 & -76 \\
\hline & Dec & 25 & -14 & & Jun & 237 & -6 \\
\hline $\mathbf{2 0 1 6}$ & Jan & 86 & 61 & & Jul & 141 & -96 \\
\hline & Feb & 70 & -16 & & Aug & 172 & 31 \\
\hline & Mar & 71 & 1 & & Sep & 291 & 119 \\
\hline & Apr & 90 & 19 & & Oct & 304 & 13 \\
\hline & May & 109 & 19 & & Nov & 298 & -6 \\
\hline & Jun & 94 & -15 & & Dec & 237 & -61 \\
\hline & Jul & 59 & -35 & $\mathbf{2 0 1 9}$ & Jan & 499 & 262 \\
\hline
\end{tabular}




\begin{tabular}{|l|l|l|l|l|l|l|l|}
\hline & Aug & 50 & -9 & & Feb & 527 & 28 \\
\hline & Sep & 143 & 93 & & Mar & 542 & 15 \\
\hline & Oct & 155 & 12 & & Apr & 451 & -91 \\
\hline & Nov & 149 & -6 & & May & 393 & -58 \\
\hline & Dec & 114 & -35 & & Jun & 330 & -63 \\
\hline $\mathbf{2 0 1 7}$ & Jan & 145 & 31 & & Jul & 190 & -140 \\
\hline & Feb & 168 & 23 & & Aug & 248 & 58 \\
\hline & Mar & 118 & -50 & & Sep & 411 & 163 \\
\hline & Apr & 110 & -8 & & Oct & 489 & 78 \\
\hline & May & 151 & 41 & & Nov & 534 & 45 \\
\hline & Jun & 153 & 2 & & Dec & 416 & -118 \\
\hline
\end{tabular}

Table 23: ARIMA - Linear Regression Analysis of differentiated values SUMMARY OUTPUT

\begin{tabular}{lr}
\hline \multicolumn{2}{c}{ Regression Statistics } \\
\hline Multiple R & 0.897544 \\
R Square & $\mathbf{0 . 8 0 5 5 8 6}$ \\
Adjusted R & \\
Square & 0.802175 \\
Standard Error & 64.7306 \\
Observations & 59 \\
\hline
\end{tabular}

\begin{tabular}{|c|c|c|c|c|c|}
\hline & $d f$ & $S S$ & $M S$ & $F$ & $\begin{array}{c}\text { Significance } \\
F \\
\end{array}$ \\
\hline Regression & 1 & 989639.8 & 989639.8 & 236.1881 & $6.25 \mathrm{E}-22$ \\
\hline Residual & 57 & 238832.9 & 4190.05 & & \\
\hline Total & 58 & 1228473 & & & \\
\hline
\end{tabular}

\begin{tabular}{|c|c|c|c|c|c|c|c|c|}
\hline & Coefficients & $\begin{array}{l}\text { Standard } \\
\text { Error }\end{array}$ & $t$ Stat & $P$-value & Lower 95\% & $\begin{array}{c}\text { Upper } \\
95 \%\end{array}$ & $\begin{array}{l}\text { Lower } \\
95.0 \% \\
\end{array}$ & $\begin{array}{l}\text { Upper } \\
95.0 \% \\
\end{array}$ \\
\hline Intercept & 25.79207 & 14.20548 & 1.815642 & 0.074686 & -2.65391 & 54.23805 & -2.65391 & 54.23805 \\
\hline $\mathrm{t}-1$ & 0.902539 & 0.058727 & 15.36841 & $6.25 \mathrm{E}-22$ & 0.78494 & 1.020137 & 0.78494 & 1.020137 \\
\hline
\end{tabular}

\begin{tabular}{|l|l|}
\hline & ARIMA $(1,1,0) \mathrm{C}$ \\
\hline Constant Drift & 0.036 \\
\hline AR (1) & 0.902 \\
\hline
\end{tabular}

\section{ARIMA - Prediction Values for actual data (2015 - 2019)}

Ytf - Forecasting values for actual data

\begin{tabular}{|l|l|l|l|l|l|l|l|l|l|}
\hline Year & Month & Yt & DYt & Ytf & \multicolumn{5}{|l|}{$\mid$} \\
\hline $\mathbf{2 0 1 5}$ & Jan & 14 & 0 & 14 & & Jul & 117 & -36 & 154.84 \\
\hline & Feb & 32 & 18 & 32 & & Aug & 129 & 12 & 84.564 \\
\hline
\end{tabular}




\begin{tabular}{|l|l|l|l|l|l|l|l|l|l|}
\hline & Mar & 49 & 17 & 48.272 & & Sep & 245 & 116 & 139.86 \\
\hline & Apr & 52 & 3 & 64.37 & & Oct & 203 & -42 & 349.668 \\
\hline & May & 42 & -10 & 54.742 & & Nov & 297 & 94 & 165.152 \\
\hline & Jun & 47 & 5 & 33.016 & & Dec & 232 & -65 & 381.824 \\
\hline Jul & 28 & -19 & 51.546 & $\mathbf{2 0 1 8}$ & Jan & 230 & -2 & 173.406 \\
\hline & Aug & 46 & 18 & 10.898 & & Feb & 291 & 61 & 228.232 \\
\hline & Sep & 90 & 44 & 62.272 & & Mar & 299 & 8 & 346.058 \\
\hline & Oct & 91 & 1 & 129.724 & & Apr & 319 & 20 & 306.252 \\
\hline & Nov & 39 & -52 & 91.938 & & May & 243 & -76 & 337.076 \\
\hline & Dec & 25 & -14 & -7.868 & & Jun & 237 & -6 & 174.484 \\
\hline $\mathbf{2 0 1 6}$ & Jan & 86 & 61 & 12.408 & & Jul & 141 & -96 & 231.624 \\
\hline & Feb & 70 & -16 & 141.058 & & Aug & 172 & 31 & 54.444 \\
\hline & Mar & 71 & 1 & 55.604 & & Sep & 291 & 119 & 199.998 \\
\hline & Apr & 90 & 19 & 71.938 & & Oct & 304 & 13 & 398.374 \\
\hline & May & 109 & 19 & 107.174 & & Nov & 298 & -6 & 315.762 \\
\hline & Jun & 94 & -15 & 126.174 & & Dec & 237 & -61 & 292.624 \\
\hline & Jul & 59 & -35 & 80.506 & $\mathbf{2 0 1 9}$ & Jan & 499 & 262 & 182.014 \\
\hline & Aug & 50 & -9 & 27.466 & & Feb & 527 & 28 & 735.36 \\
\hline & Sep & 143 & 93 & 41.918 & & Mar & 542 & 15 & 552.292 \\
\hline Oct & 155 & 12 & 226.922 & & Apr & 451 & -91 & 555.566 \\
\hline Nov & 149 & -6 & 165.86 & & May & 393 & -58 & 368.954 \\
\hline & Dec & 114 & -35 & 143.624 & & Jun & 330 & -63 & 340.72 \\
\hline Jan & 145 & 31 & 82.466 & & Jul & 190 & -140 & 273.21 \\
\hline Feb & 168 & 23 & 172.998 & & Aug & 248 & 58 & 63.756 \\
\hline Mar & 118 & -50 & 188.782 & & Sep & 411 & 163 & 300.352 \\
\hline Apr & 110 & -8 & 72.936 & & Oct & 489 & 78 & 558.062 \\
\hline May & 151 & 41 & 102.82 & & Nov & 534 & 45 & 559.392 \\
\hline & Jun & 153 & 2 & 188.018 & & Dec & 416 & -118 & 574.626 \\
\hline
\end{tabular}

\section{ARIMA - Prediction values for past attendance (2015-2019)}

\begin{tabular}{|l|l|l|l|l|l|l|}
\hline Month & $\mathbf{2 0 1 4}$ & $\mathbf{2 0 1 5}$ & $\mathbf{2 0 1 6}$ & $\mathbf{2 0 1 7}$ & $\mathbf{2 0 1 8}$ & $\mathbf{2 0 1 9}$ \\
\hline Jan & - & 14 & 12 & 82 & 173 & 182 \\
\hline Feb & - & 32 & 141 & 173 & 228 & 735 \\
\hline Mar & - & 48 & 56 & 189 & 346 & 552 \\
\hline Apr & - & 64 & 72 & 73 & 306 & 556 \\
\hline May & - & 55 & 107 & 103 & 337 & 369 \\
\hline Jun & - & 33 & 126 & 188 & 174 & 341 \\
\hline Jul & - & 52 & 81 & 155 & 232 & 273 \\
\hline Aug & - & 11 & 27 & 85 & 54 & 64 \\
\hline Sep & - & 62 & 42 & 140 & 200 & 300 \\
\hline Oct & NaN & 130 & 227 & 350 & 398 & 558 \\
\hline Nov & NaN & 92 & 166 & 165 & 316 & 559 \\
\hline Dec & NaN & -8 & 144 & 382 & 293 & 575 \\
\hline
\end{tabular}




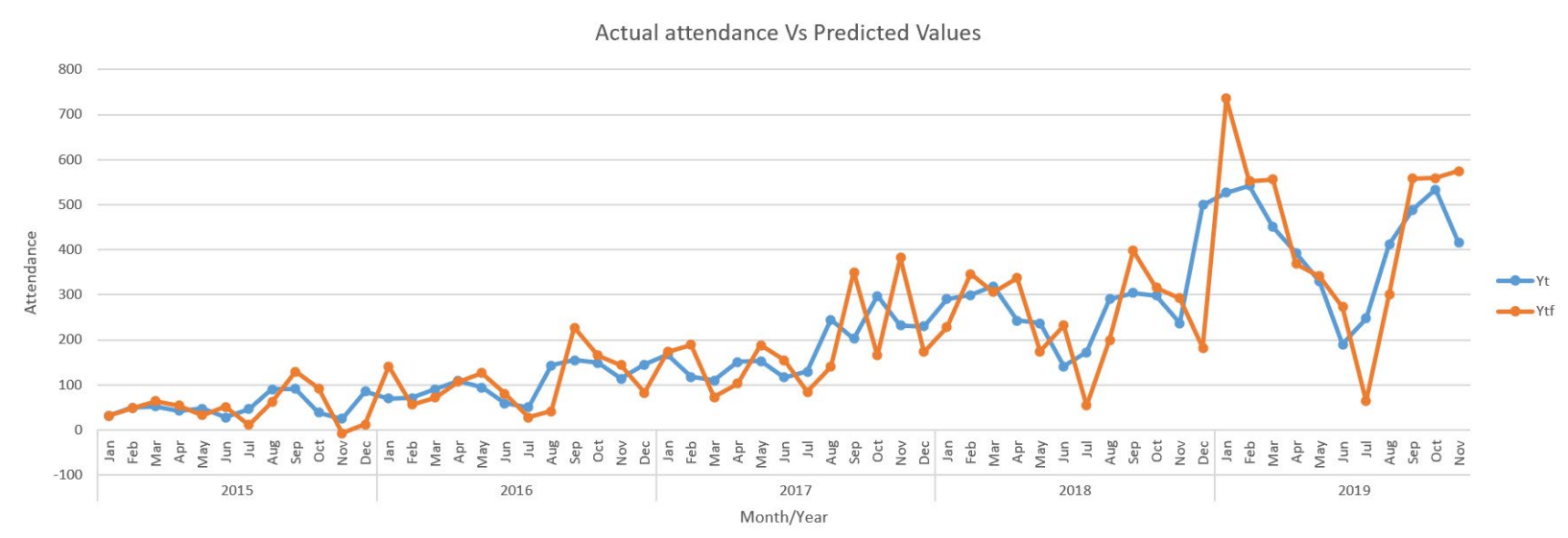

\section{Comparison of SMA and ARIMA prediction values}

- Tested both SMA and ARIMA on actual data and selected moving average model as effective based on R-square value and p-value. This step is to select appropriate time series analysis type for forecasting, compared R-square value and p-value through basic regression test. Selected Moving average model which got high Rsquare value 0.87 and less $\mathrm{p}$ - value $3.36 \mathrm{E}-28$ at $95 \%$ confidence interval as better model for forecasting.

- In evaluating performance metrics (error measures) in either machine learning regression, forecasting techniques and prognostics, scale-dependent measures like Mean Square Error (MSE), Mean Absolute Error (MAE) and measures based on percentage errors such as Mean Absolute Percentage Error (MAPE) are widely used due to their high efficiency. Tested through calculating error values for actual values and predicted values of monthly data from Jan 2015- Jan 2019 for both Simple Moving Average model and ARIMA model. 
a) Mean Absolute Error - Average of the forecast error values, where all the forecast error values are forced to be positive.

\section{MAE $/$ MAD $=$ ABS (Actual value - Predicted value)}

b) Mean Square Error - Average of squared forecast error values to force them to be positive and it has the effect of putting more weight on large errors.

$$
\mathrm{MSE}=(\text { Actual value }- \text { predicted value })^{\wedge} 2
$$

c) Mean Absolute Percentage Error - Measures the size of the error in percentage terms and expresses accuracy as a percentage of the error.

MAPE $=$ ABS (Actual value - Predicted value)/Actual value

Comparison of Simple Moving Average and ARIMA forecasting models

\begin{tabular}{|c|c|c|l|}
\hline Error tests & MA Values & ARIMA Values & \multicolumn{1}{|c|}{ Reference Values } \\
\hline MAE/MAD & 38.90 & 61.82 & 0 to $\infty$ (Lower values are better) \\
\hline MSE & 2552.15 & 7198.88 & $-10,000-+10,000$ \\
\hline MAPE & $32.9 \%$ & $37.7 \%$ & $\begin{array}{l}<10 \% \text { is Excellent, } \\
<20 \% \text { is Good }\end{array}$ \\
\hline R-square value & 0.878 & 0.805 & \\
\hline p-value & $3.36 \mathrm{E}-28$ & $6.25 \mathrm{E}-22$ & \\
\hline
\end{tabular}

\section{Forecasting values $(2020-2025)$}

Future Predicted Attendance (Simple Moving Average Forecasting) (2020-2025)

\begin{tabular}{|l|l|l|l|l|l|l|}
\hline Month & $\mathbf{2 0 2 0}$ & $\mathbf{2 0 2 1}$ & $\mathbf{2 0 2 2}$ & $\mathbf{2 0 2 3}$ & $\mathbf{2 0 2 4}$ & $\mathbf{2 0 2 5}$ \\
\hline Jan & 514 & 621 & 729 & 837 & 945 & 1052 \\
\hline Feb & 538 & 649 & 760 & 871 & 981 & 1092 \\
\hline Mar & 497 & 597 & 698 & 799 & 899 & 1000 \\
\hline Apr & 484 & 580 & 676 & 773 & 869 & 965 \\
\hline May & 470 & 562 & 654 & 746 & 839 & 931 \\
\hline Jun & 440 & 525 & 610 & 694 & 779 & 864 \\
\hline Jul & 269 & 320 & 371 & 422 & 473 & 524 \\
\hline Aug & 308 & 366 & 423 & 481 & 538 & 596 \\
\hline Sep & 608 & 720 & 832 & 944 & 1056 & 1168 \\
\hline Oct & 606 & 716 & 826 & 936 & 1045 & 1155 \\
\hline Nov & 511 & 603 & 694 & 785 & 876 & 968 \\
\hline Dec & 383 & 450 & 518 & 585 & 652 & 720 \\
\hline
\end{tabular}


Timeseries of number of attendees in all ECHO Sessions - Actual (2015 - 2019) Vs SMA

Forecasting (2020-2025)

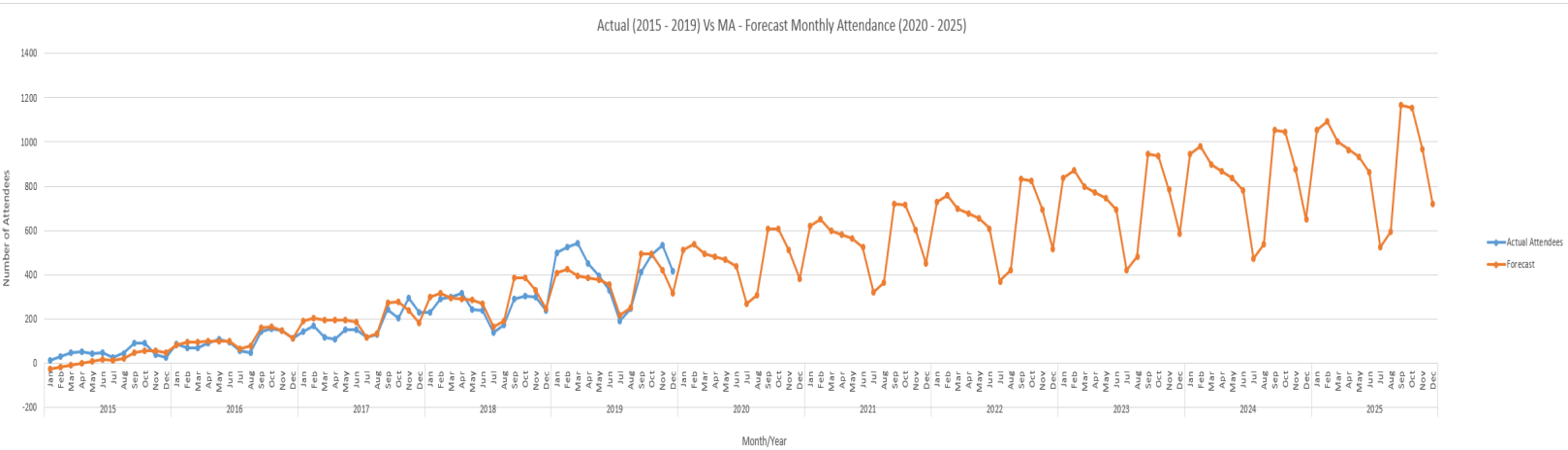

